\title{
A new genus of Lauxaniidae (Diptera) from New Caledonia
}

\author{
STEPHEN D. GAIMARI
}

California State Collection of Arthropods, California Department of Food \& Agriculture, Plant Pest Diagnostics Branch, 3294 Meadowview Road, Sacramento, CA 95832-1448, USA, email: sgaimari@cdfa.ca.gov

\begin{abstract}
The new genus Evertomyia (Diptera: Lauxaniidae) from New Caledonia is described and illustrated, along with six new species, albeto, frankadelia, irwini, helenae, matilei and webbi. Phylogenetic relationships among the six species are hypothesized, character states are discussed, and a key to the genus and its species is provided.
\end{abstract}

Key words: Diptera, Lauxaniidae, Evertomyia, new genus, new species, New Caledonia

\section{Introduction}

The fauna of Lauxaniidae (Diptera) of New Caledonia is very poorly known, although that of the larger surrounding region is extremely diverse. Endemicity in lauxaniids is very typical for this region, where nearly half of the family's diversity at the genus-group level occurs. Nearly half of the genera and subgenera found in this region (and nearly one-third of the species) are found only on Pacific islands, and 29 are endemic to single islands. Several species from other parts of the region, including Steganopsis melanogaster (Thompson 1869) from Australia, and Homoneura (Homoneura) horvathi (Kertész 1900) and $H$. (H.) varia (Kertész 1900) from New Guinea, were subsequently recorded from New Caledonia (Curran 1929), and an additional species, H. (H.) subnuda Malloch (1940), was described from the island. The current study adds a new genus endemic to New Caledonia, with six new species.

\section{Materials and Methods}

Specimens for this study are from several sources: the Illinois Natural History Survey, Champaign (INHS), resulting from the extensive collecting efforts in New Caledonia by 

toire Naturelle, Paris (MNHN); the Bernice P. Bishop Museum, Honolulu (BPBM); the Australian Museum, Sydney (AMSA); and the Queensland Museum, Brisbane (QMBA). Holotypes were deposited in BPBM and MNHN, and some paratypes were also distributed to the following collections: American Museum of Natural History, New York (AMNH), Australian National Insect Collection, Canberra (ANIC), the Natural History Museum, London (BMNH), California Academy of Sciences, San Francisco (CASC), China Agricultural University collection, Beijing (CAUC), Canadian National Collection of Insects, Ottawa (CNCI), California State Collection of Arthropods, Sacramento (CSCA), University of Guelph collection, Guelph (DEBU), Essig Museum of Entomology, Berkeley (EMEC), Hungarian Natural History Museum, Budapest (HNHM), Kyushu University Museum, Fukuoka (KUEC), Museum of Comparative Zoology, Cambridge (MCZC), Muséum d'Histoire Naturelle, Geneva (MHNG), Museu de Zoologia, São Paulo (MZSP), Naturhistorisches Museum, Wien (NHMW), Natal Museum, Pietermaritzburg (NMSA), Bohart Museum of Entomology, Davis (UCDC), National Museum of Natural History, Washington DC (USNM), Zoological Institute, Russian Academy of Sciences, St Petersburg (ZISP), Zoological Museum of Humboldt University, Berlin (ZMHB), and Zoological Museum of the University of Copenhagen (ZMUC).

Terminology. Basic terminology follows McAlpine (1981) and Shewell (1987). Body length was measured by adding the length of the head (without antennae) through the thorax with the abdominal length, to account for differential curling of the abdomens among specimens. For head ratios: the head length and height were measured from lateral view, respectively, from the tip of the frons through the posterior occiput, and from the ocelli through the bottom edge of the gena; the head width, frons width, and frons length were measured from dorsal view, with head width measured through the widest part, frons width through the anterior ocellus, and frons length from the anterior ocellus through the anterior edge of the frons. On the thorax, the scutal width is measured at the level of the supra-alar setae, and the scutellar width is measured through the area of contact with the scutum. In the wing, the width was measured at the level just proximal to the tip of $\mathrm{CuA}_{1}$; the discal medial cell length was measured from the bm-cu crossvein through the anterior tip of the dm-cu crossvein. All other measurements were made through their maximum widths, lengths, heights, etc. Note, some specimens have a thin, slightly lighter median longitudinal line (Fig. 2), which appears to be a lightening of the cuticle between muscle attachments as an artifact of drying.

Systematics. Cladistic phylogenetic analyses follow the principles, philosophies, and specific methods outlined in Gaimari \& Irwin (2000). Character polarities were determined using an outgroup taxon chosen within the context of hypothesized relationships among lauxaniid genera. Although there is no published hypothesis on relationships of lauxaniid genera, the genus Protrigonometopus Hendel seems to be a reasonable choice as an outgroup based upon several important shared characteristics, mostly on the head, e.g., 
the frons are oriented horizontally in line with the scutum, the lateral edges of the frons are slightly divergent anteriorly, the frons bulges forward beyond the eye with a fronto-facial angle of $90^{\circ}$ or less, setulae are present on the anterior part of the frons, and the scutellum is flattened. Because specimens of the type species, P. maculifrons Hendel, were unavailable, specimens of a closely related, but as yet undescribed, species were utilized. The $5 \sigma^{x}$ and 5 o specimens all have the following label data "Nepal, Kakani, 5-V-1980, Amnon Freidberg", and are housed in the USNM. One ơ and one 9 were dissected, with SDG dissection \#s 1241 and 1242 respectively.

Cladistic analyses were performed using the exhaustive search option in PAUP*, Beta version 4.0 (Swofford 1999), and data were subjected to successive approximations character weighting (Carpenter 1988), an a posteriori weighting scheme implemented in PAUP* by reweighting all characters on a base weight of 1000 according to the maximum values of their rescaled consistency indices. Following the reasoning discussed by Gaimari \& Irwin (2000), only Bremer support was analyzed to assess the robustness of elements of the cladogram. Acquiring Bremer support values entails calculating the difference in length between the most parsimonious cladogram and the shortest cladogram that lacks each nodal group. This reflects how much additional evidence, in the form of characters supporting an alternative grouping, would be necessary to overthrow the individual nodes in the most parsimonious hypothesis. Using PAUP*, Bremer support indices were calculated manually for each nodal group in the cladogram by incrementally adding 1 to the tree length in an exhaustive search (e.g., "alltrees keep $=54$ " for 1 extra step) to determine which nodes were lost. Following Gaimari \& Irwin (2000), Bremer support indices were also calculated using the successively reweighted data, and were rescaled per the procedure outlined by Bremer (1994), agreeing that this reflects the amount of realistic character data, subject to a posteriori reweighting, that would be necessary to overthrow a given clade. Manual calculation in this latter case entailed incrementally adding to the shortest tree length after reweighting (the increments are quite simple to calculate in PAUP*, as the values for each step are displayed in a "frequency distribution" bar chart of tree scores), performing another exhaustive search, viewing a consensus cladogram (with nodes collapsed) and then applying Bremer's (1994) procedure for rescaling the values.

The data matrix used in these analyses is shown in Table 1. Of the 37 characters considered (see below), 32 were binary and 5 were unordered tertiary, with 15 from the head, 7 from the thorax, legs, and wings, 2 from the abdomen, 5 from the male genitalia, and 8 from the female terminalia. The most parsimonious cladogram was prepared using WINCLADA version 1.00.08 (Nixon 2002) under ACCTRAN (= "fast" in WINCLADA parlance) character optimization (Swofford \& Maddison 1987), following the reasoning of Gaimari \& Irwin (2000).

Morphological characters. Following are the characters used for cladistic phylogenetic analysis of species of Evertomyia. Plesiomorphic states, as determined using the outgroup genus Protrigonometopus, are indicated by (0). 
449 1. Placement of ocellar triangle: $0=$ at level of vertex; $1=$ anterior to vertex.

2. Ocellar setae: $0=$ weak; $1=$ strong.

3. Ocellar setae: $0=$ divergent; $1=$ proclinate and parallel-sided.

4. Frontal vitta: $0=$ setulose; $1=$ bare.

5. Fronto-orbital plate: $0=$ even with frontal vitta; $1=$ raised from frontal vitta.

6 . Fronto-orbital plate: $0=$ pruinose, but not entirely silvery grey; $1=$ entirely silvery grey pruinose; 2 = lacking pruinescence.

7. Anterior part of fronto-orbital plate: $0=$ setulose, but reclinate or proclinate only; $1=$ with inclinate and reclinate, and reclino-inclinate setulae.

8. Pruinose spot below fronto-orbital plate: $0=$ present; $1=$ absent.

9. Anterior orbital seta: $0=$ closer to lunule edge; $1=$ closer to posterior orbital seta.

10. Ptilinial suture: $0=$ without dark edge; $1=$ edge darkened only in dorsal part; $2=$ entire suture with dark edge.

11. Antennal groove: $0=$ absent; $1=$ normal, not darkened; $2=$ distinctly darkened below antenna.

12. Dorsal part of face: $0=$ flattened; $1=$ pinched inwards into facial carina.

13. Median facial spot: $0=$ present; $1=$ absent.

14. Paired spots on ventral part face: $0=$ absent; $2=$ present.

15. Antennal arista: $0=$ pubescent, longest rays $0.3 \mathrm{X}$ height of 1 st flagellomere or less; 1 $=$ short plumose, longest rays $0.4 \mathrm{X}$ height of 1 st flagellomere or greater.

Thorax

16. Scutum: 0 = with silvery grey pruinescence; 1 = lacking silvery grey pruinescence.

17. Dorsocentral vittae: $0=$ absent; $1=$ present.

18. Base of anepisternal seta: $0=$ lacking spot; $1=$ with distinct spot.

19. Tibiae: 0 = lacking bands; 1 = with basal, sub-basal, and apical brown bands.

20. Midtibial spurs: $0=$ one; $1=$ two.

21. Wing vein $\mathrm{A}_{1}+\mathrm{CuA}_{2}: 0=$ short, ending well before wing margin; $1=$ visible nearly to wing margin.

22. Color of halter knob: $0=$ darkened; 1 = yellow.

Abdomen

23. Spots on lateral parts of tergites: $0=$ absent; $1=$ present.

24. Sternites $2-5$ of male: $0=$ as wide as long; $1=$ two times wider than long.

Male genitalia

25. Surstylus: $0=$ blunt; $1=$ gradually tapering; $2=$ thick basally, then abruptly tapering.

26. Surstylus: $0=$ fixed to epandrium; $1=$ articulated with epandrium.

27. Anterior edge of hypandrium: $0=$ straight; $1=$ concave. 
28. Paired lateral lobes of hypandrium: $0=$ present, posteriorly directed, with setulae at tip; 1 = absent.

9. Paramere: $0=$ absent; $1=$ present, tusk-like.

Female terminalia

30. Sternite 8: $0=$ stout, length and width subequal; $1=$ elongate, longer than wide.

31. Sternite 8: $0=$ lacking pointed structures; $1=$ with medially oriented, pointed tips.

32. Lobes of sternite $8: 0=$ absent; $1=$ broad, thick; $2=$ long, thin.

33. Sternite 8: $0=$ nothing extending beyond posterior edge; $1=$ lobes extending beyond posterior edge of sternite 8 .

34. Size of single (unpaired) spermatheca: $0=$ large, $0.12 \mathrm{~mm}$ diameter or larger: $1=$ small, $0.09 \mathrm{~mm}$ diameter or smaller.

35. Spermathecae: $0=$ smooth; $1=$ with teeth in basal half.

36. Spermathecal pair: $0=$ close together; $1=$ elongate duct after branching.

37. Internal spermathecal opening: $0=$ funnel-like; $1=$ with lobed flaps.

TABLE 1. Data matrix for the analysis of phylogenetic relationships among species of Evertomyia.

\begin{tabular}{|c|c|c|c|c|c|c|c|c|}
\hline & 12345 & 67890 & $\begin{array}{l}11111 \\
12345\end{array}$ & $\begin{array}{l}11111 \\
67890\end{array}$ & $\begin{array}{l}22222 \\
12345\end{array}$ & $\begin{array}{l}22222 \\
67890\end{array}$ & $\begin{array}{l}33333 \\
12345\end{array}$ & $\begin{array}{l}33 \\
67\end{array}$ \\
\hline Protrigonometopus & 00000 & 00000 & 00000 & 00000 & 00000 & 00000 & 00000 & 00 \\
\hline E. albeto & 11111 & 11012 & 11010 & 01011 & 10101 & 10000 & 01101 & 10 \\
\hline E. frankadelia & 10011 & 01110 & 11100 & 10000 & $100 ? ?$ & ????1 & 12100 & 01 \\
\hline E. helenae & 11111 & 01001 & 21111 & 01110 & 11102 & 11100 & 01010 & 00 \\
\hline E. irwini & 11111 & 11001 & 21111 & 01010 & 11111 & 10110 & 01000 & 00 \\
\hline E. matilei & 11111 & 11001 & 21110 & 00110 & 11102 & 11000 & 01110 & 00 \\
\hline E. webbi & 10011 & 21100 & 11101 & 10000 & 10000 & 10111 & 12100 & 00 \\
\hline
\end{tabular}

\section{Evertomyia, gen. nov.}

Type species. Evertomyia irwini, sp. nov. (Fig. 1), by present designation.

Etymology. Named in honor of my friend and fellow dipterist, Dr. Evert I. Schlinger.

Diagnosis. Large sized flies ( $>5 \mathrm{~mm}$ ); body color generally orange, variously with silvery or bronzy grey pruinescence. Frons with lateral edges slightly divergent anteriorly, nearly horizontal and in plane with scutum, bulging forward beyond eye margin; frontal vitta orange, bare of setulae; fronto-orbital plates distinct, slightly raised from frontal vitta, with dense medially oriented setulae on anterior half. Face bulging, clearly visible in profile, at right or slightly acute angle with frons, and pinched inwards in dorsal half forming antennal grooves. $0+3$ dorsocentral setae. Scutellum flat. Wing veins $A_{1}+C u A_{2}$ and $A_{2}$ parallel, elongated, visible almost to wing margin. In male, surstylus articulated with epan- 
drium, and aedeagus large and thick. In female, abdomen abruptly tapering after segment 5 , with syntergosternites 6 and 7 each forming a complete ring; most species with paired posteriorly oriented medial processes of sternite 8 (not protruding in one species).

Adults, $\circ^{x}$, ㅇ․ Body length 5.2-7.2 mm.

Head (Figs. 3A-F). Vertex rounded; inner vertical seta longer than outer. Ocellar triangle small, slightly raised, placed anterior to vertex. Ocellar setae strong (as strong as anterior orbital seta) to weak (half size of anterior orbital seta); proclinate and parallel-sided to divergent, arising along or just outside imaginary line between anterior and posterior ocelli; several pairs of small variously oriented setulae located from postocellar setae through ocellar triangle, those behind ocellar triangle usually convergent. Postocellar setae cruciate. Postocular setae in 2 distinct rows; those of anterior row stronger, curved outward, in line with and in same orientation as outer vertical seta; those of posterior row curved inward; posterior row extends onto vertex. Frons 1.0-1.2 X broader than long; with lateral edges slightly divergent anteriorly; oriented horizontally, in line with scutum, bulging forward beyond eye; anterolateral part of frons visible in profile, some species with pruinose spot visible in profile below fronto-orbital plate. Frontal vitta orange, with light dusting of silvery or bronzy pruinescence visible only from certain aspects; slightly converging anteriorly; bare of setulae. Fronto-orbital plate slightly raised from frontal vitta; anterior part (anteriorly from posterior orbital seta) with smaller inclinate, reclinate, and reclino-inclinate setulae, becoming more numerous, stronger, and more inclinate anteriorly. Orbital setae reclinate; posterior seta stronger than anterior, although only slightly so in most species. Antennal 1st flagellomere with rounded apex; arista dark brown, short plumose (longest rays $0.8-1.5 \mathrm{~mm}, 0.4-0.8 \mathrm{X}$ height of 1st flagellomere) or pubescent (pubescence no longer than $0.5 \mathrm{~mm}$, and less than $0.3 \mathrm{X}$ height of 1 st flagellomere). Face bulging, clearly visible in profile, at right or slightly acute angle with frons; pinched inwards in dorsal half forming apparent antennal grooves, with facial carina at least slightly keeled; ventral part of face with or without paired dark brown pruinose spots. Gena with several fine anteriorly-directed setulae near oral margin and extending onto ventral parafacial. Prementum dull brown; with several long black setulae.

Thorax (Fig. 2). Scutum only slightly arched, covered with small setulae, in 8 rows between dorsocentral setae (except $E$. matilei with 6 rows); with or without silvery grey or bronzy grey dorsocentral vittae. Scutellum flat. Chaetotaxy (Fig. 2): 0+3 dorsocentral setae; 1 postpronotal seta; 2 notopleural setae, in anterior and posterior corners; presutural intra-alar seta present; 1 supra-alar seta; 1 intra-alar seta (located between posterior dorsocentral and postalar setae); 1 postalar seta; 1 prescutellar acrostichal seta; 1 proepisternal seta at ventral tip; 1 strong anepisternal seta in posterodorsal third of anepisternum, anepisternum otherwise with small setulae; anepimeron bare; 2 strong katepisternal setae, anterior seta weaker than posterior, katepisternum otherwise with fine setulae and with 4-7 larger setae ventrally near midline; 2 pairs scutellar setae, posterior pair cruciate. Legs. Forefemur slightly swollen relative to midfemur; ctenidium present, but in some species 
setulae more widely spaced than a typical ctenidium (0.15-0.36 mm apart, 7-16 setulae); with posterodorsal and posteroventral rows of strong setae, posteroventral setae strongest; posterior surface with 1 to several smaller setae. Foretibia with 1 subapical dorsal seta; with apical comb of fine golden hairs anteroventrally. Midfemur with row of strong setae on distal half of anterior surface; strong curved seta present posteroapically, in addition to several similar but weaker curved setae dorsoapically. Midtibia with 1 subapical dorsal seta, 1 or 2 strong tibial spurs, and several short but thick spurs. Hindfemur with inner surface shiny orange and without pruinescence or setulae; with preapical anterodorsal seta. Hindtibia with weakly developed subapical dorsal seta; with apical comb of fine golden hairs posteroventrally. Wing. Hyaline, with yellow tint darkest on anterior half; sapromyziform (setulae along costa reach point between $\mathrm{R}_{2+3}$ and $\mathrm{R}_{4+5}$ ). Crossvein $\mathrm{r}-\mathrm{m}$ slightly beyond middle of discal medial cell; located slightly basal of halfway point of wing. Crossvein dm-cu straight. $\mathrm{R}_{4+5}$ and $\mathrm{M}_{1}$ subparallel to slightly converging distally. Veins $\mathrm{A}_{1}+\mathrm{Cu} \mathrm{A}_{2}$ and $\mathrm{A}_{2}$ parallel, elongated, visible almost to wing margin.

Abdomen. Syntergite 1+2 through tergite 5 each laterally wrapped under abdomen, setulose, with transverse row of long setae along posterior edge. In male, sternites $2-5$ as long as wide ( 2 x longer than wide in E. irwini), setose, with slightly longer setae along posterior and posterolateral edges; spiracles set in membrane; internally (Fig. 4) with testes large, 3-4 x longer than wide; accessory glands elongated, tangled, bifurcating, some ending in blind tubes, filling most of abdomen. In females, sternites 2-5 rectangular, wider than long, with elongated setae along posterior edge; abdomen abruptly tapering after segment 5 , syntergosternite 6 forming a complete ring with spiracle embedded laterally. Rectum with 2 pairs of rectal papillae, configured 2 on each side; distal $1 / 3$ with distinctly darkened sharp teeth.

Male genitalia. Epandrium simple, setose. Surstylus distinct, articulated with epandrium; rounded to strap-like; with or without medially oriented hook. Cercus rounded, setose. Aedeagus large, thick; usually with large longitudinal dorsomedial sharpened ridge along distal third to half; gonopore elongate along posterior edge of ridge (except $E$. matilei lacking ridge and with gonopore wide open). Paramere present or absent.

Female terminalia. Syntergosternite 7 forming a complete ring, with spiracle embedded laterally. Sternite 8 with paired posteriorly oriented medial processes, although not protruding in one species (E. helenae). Hypoproct simple, semicircular, setulose with long hair-like setae along posterior edge; epiproct simple, semicircular, setulose, with pair of long hair-like setae in middle; cercus simple, setulose, with several longer hair-like setae. Spermathecae with configuration $2+1$; single spermatheca largest; pair usually closely linked at bifurcation (except in E. albeto); each internally smoothly funneled into spermathecal duct (Fig. 9E) (except E. frankadelia with internal lobes); smooth over external surface (except $E$. albeto with small teeth and bumps sub-basally).

Immatures. Egg stage. Elongate; slightly curved in lateral view (Fig. 7D); parallel sided from dorsal view; with distinct longitudinal ridges with uniform striations between. 
Micropylar end either continuous with shape of egg (Fig. 7D) or protruding and globose (Fig. 11C). Eclosion end with series of protruding lobes (3 on each side) (Fig. 7E), reduced to small bumps in some species (Fig. 13D).

Distribution. Known only from rainforest areas of New Caledonia.

Biology. Specific larval biology unknown, but likely feeding within rainforest leaf litter, or other decomposing vegetation, as is typical for Lauxaniidae. Adults associated almost entirely with tropical rainforests in the mountains and valleys of New Caledonia. The species are often collected along streams and forest paths, and some species are attracted to human feces and wallaby dung.

Remarks. This new genus is superficially similar to some species of the genus Sapromyza Fallén in its broadest, polyphyletic sense (i.e., it keys to Sapromyza in Stuckenberg (1971), as do many undescribed genera that are not related to Sapromyza in the true sense of Sapromyza obsoleta Fallén). It is also superficially similar to some of the Trigonometopus-like genera (e.g., Diplochasma Knab, Maquilingia Malloch, Neotrigonometopus Malloch, Oncodometopus Shewell, Trigonometopsis Malloch, Trigonometopus Macquart) in having the frons bulging beyond the eye margin, the frons having setulae on the anterior part of the frons, and having the head nearly horizontal and in plane with the scutum, but in these genera the body and head are more elongate, the body size is usually smaller, the setulae on the frons are all proclinate with few if any oriented medially, the frontal vitta is not distinctly bare of setulae, the fronto-orbital plates are not raised from the frontal vitta, the oral margin and ventral parafacial are bordered by elongated setae, the arrangement of dorsocentral setae is usually different (e.g., $1+2$, or $0+3$ with the anterior seta close to the mesonotal suture), the scutal setulae are quite sparse (e.g., often only 1-2 acrostichal rows), and the presutural supra-alar seta is usually absent or reduced. Some large-bodied genera also have setulae on the anterior part of the frons (e.g., Euprosopomyia Malloch, Longifrons Kim), but in these genera, the fronto-facial angle is distinctly obtuse with the frons being more or less in line with the face, and the costa is homoneuriform (setulae reach the apex of $\mathrm{R}_{4+5}$ ). For smaller bodied genera, some also have the anterior setulae on the frons (e.g., Hendelimyza Frey), but the setulae are distinctly proclinate and encompass the entire width of the frons. The general thick body form displays the gestalt of some species of Minettia Robineau-Desvoidy, but there are at most minute setulae on the frons, including the frontal vitta, the fronto-facial angle is obtuse, and Evertomyia lacks the postsutural intra-alar seta. The general body form is also similar to some larger species of Homoneura Wulp sensu lato, but the setulae on the frons, if present, are never arranged as in Evertomyia, and the wing is homoneuriform in all species of Homoneura. Also, the elongated vein $\mathrm{A}_{1}+\mathrm{CuA}_{2}$ is unique in Evertomyia among the genera with superficial similarities. 


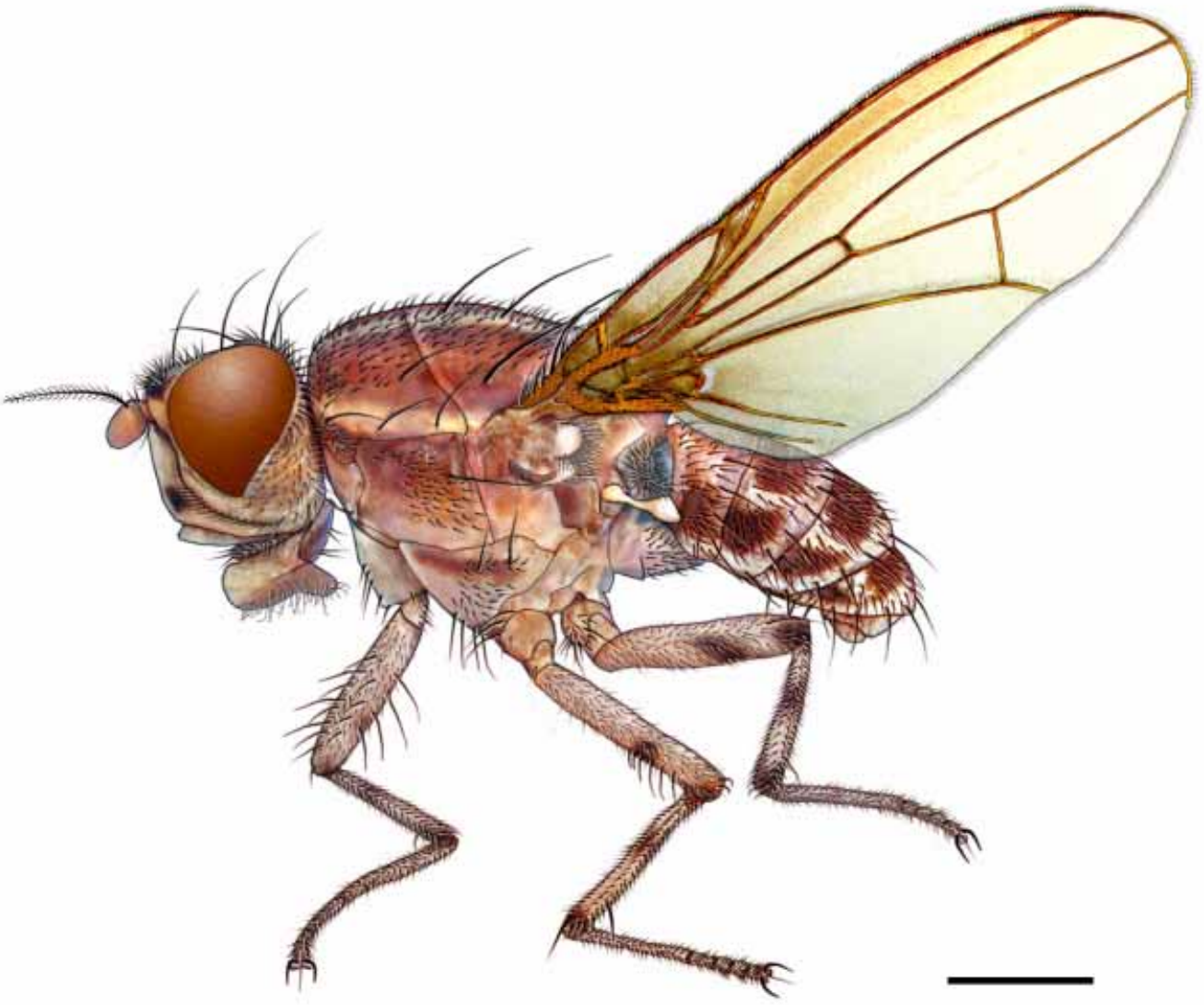

ZOOTAXA

FIGURE 1. Evertomyia irwini, sp. nov. $0^{x}$. Habitus, lateral view. Scale bar $=1.0 \mathrm{~mm}$.

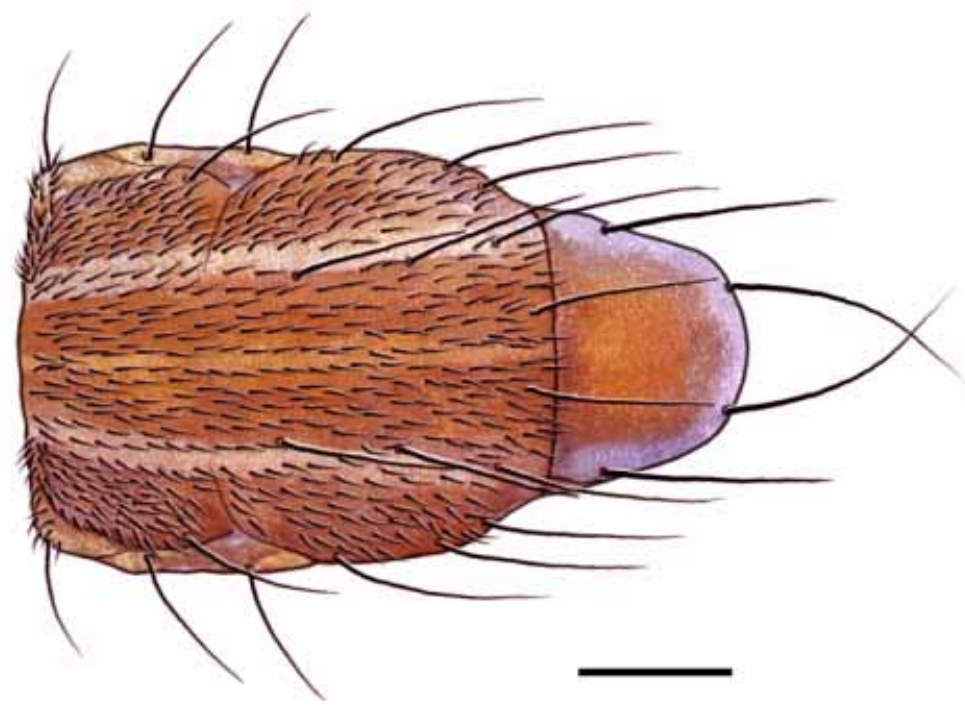

FIGURE 2. Evertomyia helenae, sp. nov. $0^{x}$. Thorax, dorsal view. Scale bar $=0.5 \mathrm{~mm}$. 

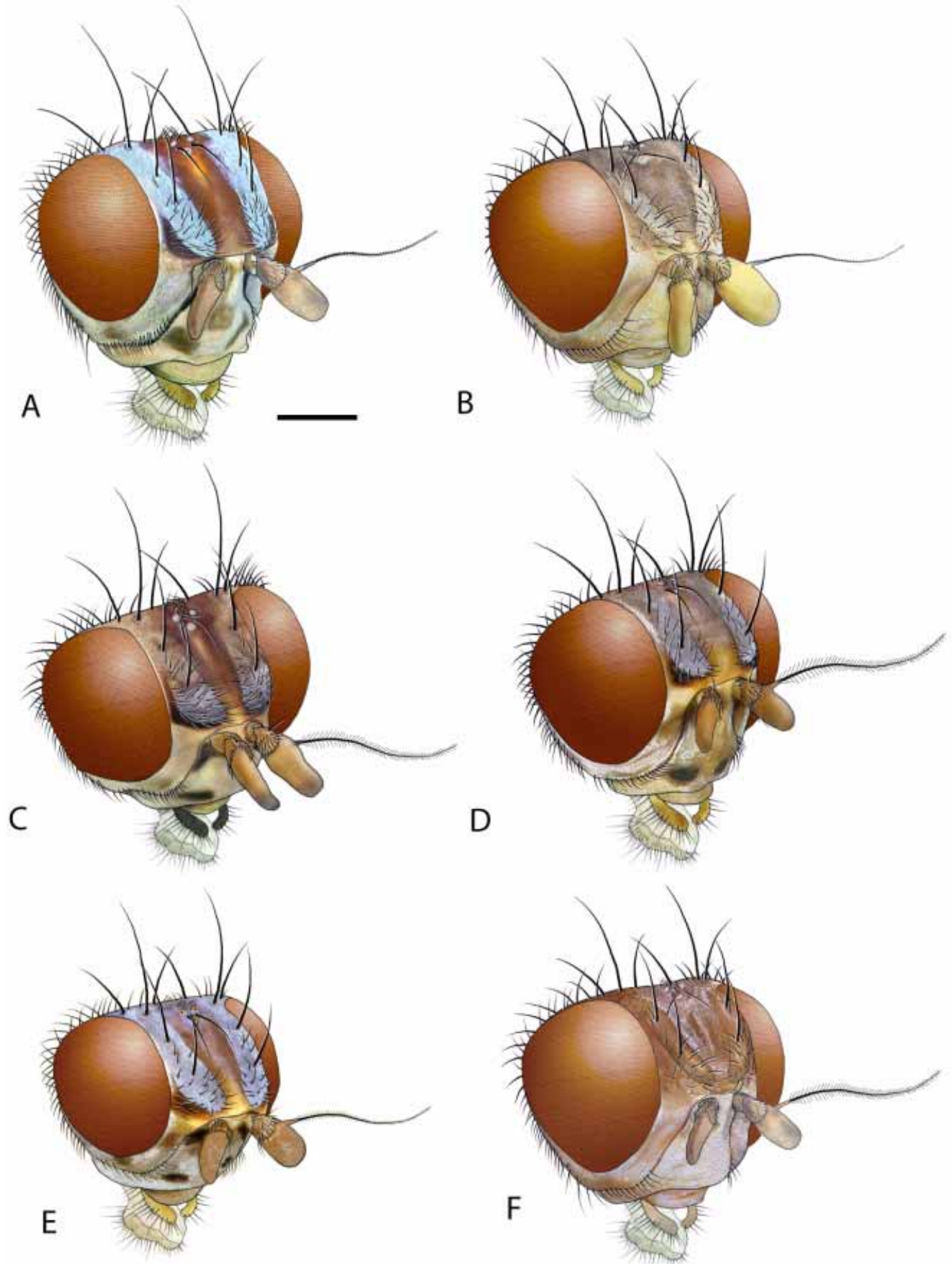

FIGURE 3. Head, oblique view, right arista removed for clarity. Scale bar $=0.5 \mathrm{~mm}$. A) Evertomyia albeto, sp. nov. ơ. B) Evertomyia frankadelia, sp. nov. ㅇ.ᅮ C) Evertomyia helenae, sp. nov. 우. D) Evertomyia irwini, sp. nov. ‥ E) Evertomyia matilei, sp. nov. ơ. F) Evertomyia webbi, sp. nov. 우. 
Although many undescribed genera key to "Sapromyza" using Stuckenberg's (1971) key, including Evertomyia, a relatively simple modification earlier in the key pulls out this new genus. Stuckenberg's (1971) key should be modified as follows, at couplet 66:

66. Fronto-facial angle from right-angled to acute, bulging forward beyond eye margin (e.g., Fig. 1). Frons nearly horizontal, and conspicuously setulose anteriorly. 0+3 dorsocentral setae $66 \mathrm{~A}$

- Without this combination of characters 67

66A. Frontal vitta distinct, completely bare, orange (Figs. 3A-F). Fronto-orbital plates distinct, slightly raised from frontal vitta, with dense medially oriented setulae on anterior half (Figs. 3A-F). Face pinched inwards on dorsal part directly below antennae. Ocellar setae normal sized, proclinate, parallel-sided (as in Figs. 3A, C-E) to slightly divergent (as in Figs. 3B, F). Scape hidden, conspicuously shorter than pedicel. Large species, $>5 \mathrm{~mm}$. Evertomyia gen. nov.

- $\quad$ Fronto-orbital plates not raised from frontal vitta, which is usually indistinct; setulae dispersed across width of anterior part of frons, not curved into medial orientation. Face relatively flat, not pinched inwards on dorsal part. Ocellar setae small, divergent. Scape fully exposed, nearly as long as pedicel. Small species, $<5 \mathrm{~mm}$..... 66B

66B. Head with acute fronto-facial angle of about $70^{\circ}$. Orbital setae normal, anterior seta located on anterior part of frons. Often with large, black pruinose spot between antenna and eye. Intradorsocentral setulae in single row (acrostichal setulae only) ... Protrigonometopus Hendel (1938)

- Head with right fronto-facial angle of $90^{\circ}$. Orbital setae small, both located in posterior half of frons. Lacking spot between antenna and eye. Intradorsocentral setulae quadriseriate Hendelimyza Frey (1927)

\section{Key to the species of Evertomyia}

1. Face with paired black spots on ventral portion (e.g., Figs. 3A, C-E). Frons with fronto-orbital plates silvery grey pruinose (Figs. 3A, E), at least in part (Figs. 3CD). Scutum with dorsocentral vittae or with entire dorsal part silvery grey.

- $\quad$ Face without darkened spots (Figs. 3B, F). Fronto-orbital plates easily differentiated from remainder of frons, but not silvery grey (Figs. 3B, F). Scutum neither vittate nor dorsally silvery grey

2 (1). Anterior orbital seta smaller than outer vertical seta, located near middle of frons length; fronto-orbital plates light bronzy brown pruinose (Fig. 3B). Face yellowish, facial carina distinctly keeled. Antennal 1st flagellomere and maxillary palpus orange. Scutum, scutellum, and pleural area unicolorous light bronzy brown pruinose 
frankadelia, sp. nov.

- Anterior orbital seta larger than outer vertical seta, located in anterior part of frons; fronto-orbital plates shiny orange, lacking pruinescence (Fig. 3F). Face covered with silvery grey pruinescence, facial carina not keeled. Antennal 1st flagellomere and maxillary palpus dark brown. Scutum and scutellum light brownish orange; pleural area lighter colored, nearly yellow webbi, sp. nov.

3 (1). Frons with fronto-orbital plates silvery grey pruinose only anteriorly, forward of anterior orbital seta (Fig. 3C); remainder light bronzy pruinose. Scutum with light bronzy dorsocentral vittae (Fig. 2). Distinct dark stripe from proepisternum through posterior katepisternal seta helenae, sp. nov.

- Frons with fronto-orbital plates entirely silvery grey pruinose (Figs. 3A, D-E). Scutum with silvery grey dorsocentral vittae or with entire dorsal part silvery grey. Proepisternum through katepisternum variously marked, but never with entire stripe

4 (3). Scutellum and dorsal part of scutum entirely silvery grey pruinose, not vittate. Anepisternum silvery grey, with distinct darkened spot at base of anepisternal seta matilei, sp. nov.

- Scutum brownish-orange, with distinct, thin silvery grey dorsocentral vittae that extend through scutellum. Anepisternum with coloration variable, but lacking distinct spot at base of anepisternal seta

5 (4). Ptilinial suture with borders distinctly darkened, fading below level of facial spots (Fig. 3A); antennal groove at most slightly darkened, never concolorous with paired facial spots. Face with slightly to distinctly darkened median facial spot above paired facial spots and below facial carina (Fig. 3A). Midtibia with 2 strong spurs. Silvery grey vittae on scutellum extend around posterior edge, visible from dorsal view albeto, sp. nov.

- $\quad$ Ptilinial suture with border darkened only in dorsal part, fading out above level of facial spots; antennal groove distinctly darkened as medial triangular extension from dorsal part of ptilinial suture, concolorous with facial spots (Fig. 3D). Face lacking median spot. Midtibia with 1 strong spur. Silvery grey vittae on scutellum not extended around posterior edge, although posterior edge pale yellow from posterior view. irwini, sp. nov.

\section{Evertomyia albeto, sp. nov.}

(Figs. 3A, 4, 5A-D, 6A-D)

Etymology. Named for my three children, Alex ("al-"), Becky ("-be-"), and Tony ("-to").

Diagnosis. Like E. helenae, E. irwini and E. matilei, this species has strong, proclinate, parallel-sided ocellar setae, silvery grey pruinescence on the fronto-orbital plate 
(although unlike E. helenae, this pruinescence covers it entirely), and paired spots on the ventral part of the face. Unlike these species, the antennal groove lacks a distinct triangular dark brown to black mark below the antennae, although there can be slight darkening. Like E. irwini, silvery grey dorsocentral vittae are present but are wider than that species, with a width equal to half the distance between vittae; and vittae extend through the scutellum, but unlike that species they extend around the posterior edge. Like E. frankadelia and $E$. matilei, the antennal arista is pubescent. Like all species except $E$. frankadelia, the orbital setae are strong with the posterior seta slightly stronger than the anterior seta, and the anterior dorsocentral seta is closer to the transverse suture than to the middle seta. Unlike all other species, the ptilinial suture is dark brown to black pruinose along its entire length terminating below the level of paired facial spots, a median brownish spot is present on the face above the ventral paired spots and below the facial carina, the anterior orbital seta is closer to the posterior seta than to the lunule edge, the anepisternum is dark brown in the posterodorsal quadrant, and the midtibia has 2 strong spurs. In the male: the surstylus has its distal third abruptly curved, with a distinct medial ridge ventrolaterally, is setose only on the dorsal surface, and is pilose only on the dorsolateral surface; the aedeagus has the lateral distiphallus flattened, the lateral edges have serrated teeth, and the posterior edge is rounded and shovel-like; the hypandrium has a pair of posteriorly-directed lateral lobes; the paramere is absent. In the female: sternites $2-5$ are less than $2 \mathrm{X}$ broader than long; sternite 8 is nearly as broad as long, and entire (without lateral arms), and the paired central processes are greatly enlarged and broadened, lacking a distal hook; spermathecae each have minute external teeth in a sub-basal ring, and the paired spermathecae each have elongated ducts beyond their bifurcation.

Adults, ox, 오. Body length 6.4-7.2 mm.

Head (Fig. 3A). 1.1-1.3 X higher than long, 1.3-1.4 X wider than high; eye as high as long. Vertex with light dusting of silvery grey pruinescence medially, and fully pruinose laterally; outer vertical seta as strong as posterior orbital seta, inner seta 1.6-1.9 X longer. Ocellar triangle covered with same light pruinescence as medial part of vertex. Ocellar and postocellar setae strong, subequal; ocellar setae proclinate, parallel-sided. Occiput silvery grey pruinose; median occipital sclerite orange with light dusting of silvery grey pruinescence. Frons with anterolateral part with brown pruinose spot visible in profile below fronto-orbital plate. Fronto-orbital plate densely covered with silvery grey pruinescence extending posteriorly over vertex through occiput. Orbital setae strong; posterior seta slightly stronger than anterior; anterior seta arising closer to posterior seta than to edge of lunule; posterior seta arising closer to anterior seta than to inner vertical seta; distance between anterior setae subequal to that of posterior setae. Scape and area lateral to antennal base orange; facial carina pale yellow with light dusting of silver pruinescence. Antennal pedicel and 1st flagellomere orange; 1st flagellomere 1.6 X longer than high; arista pubescent. Face yellowish orange, with light dusting of silver pruinescence; antennal grooves without distinct dark marks below antenna; ptilinial suture with darkened edges 
along entire length; median light to dark brown pruinose spot below facial carina; ventral part of face with paired dark brown pruinose spots. Parafacial grey pruinose; gena and postgena yellowish orange with light covering of silver pruinescence and with darker grey pruinose area below eye. Clypeus yellowish orange. Maxillary palpus dark orange, darkening distally, darkest at tip; subcylindrical; with black setulae.

Thorax. Scutum 1.2-1.3 X longer than wide; scutellum with width at base 1.3-1.5 X greater than length; scutum and scutellum orange; wide silvery grey dorsocentral vittae present (width of vitta $=$ half width of orange area between vittae), extending through scutellum and around posterior edge, visible from dorsal view; some specimens with thin, slightly lighter median longitudinal line; postpronotal lobe through notopleuron to wing base silvery grey pruinose. Posterodorsal quadrant of anepisternum, including base of anepisternal seta dark brown; remainder of pleural region, including remainder of anepisternum, with areas of pale silvery, dark brown, and yellowish orange pruinescence. Distance between dorsocentral setae subequal, with anterior seta closer to transverse suture than to middle seta. Legs. Yellowish orange, except as noted. Coxae yellow, with light dusting of silvery white pruinescence. Forefemur mostly brownish; ctenidium present but indistinct, only distinguishable from surrounding setulae as an evenly spaced (each $0.30-0.36 \mathrm{~mm}$ apart) row of 7-9 setulae; posterior surface with 1 small seta or short row of small setae. Foretibia with brown bands sub-basally, and apically. Midfemur with brown band at midpoint, on ventral surface. Midtibia with brown bands basally, sub-basally, and apically; with 2 strong spurs. Hindfemur brownish basally and with brown pruinose band on anterior and anteroventral surfaces beyond middle and apically. Hindtibia with silvery brown bands sub-basally (corresponding in position with band on femur) and apically. Wing. Length 6.4-6.8 mm; 2.2-2.6 X longer than high. Discal medial cell 3.8-4.0 X longer than crossvein dm-cu. Halter yellow with darkened knob.

Abdomen. Yellowish orange; subequal in length to scutum. Transverse rows of long setae along posterior edges of tergites becoming longer and stronger laterally. Lateral and posterolateral edges of tergites grey pruinose; remaining lateral portions brown pruinose, with grey spot on anterior edge of each; from dorsal view, lateral brown area visible. Sternites yellow with dusting of silvery white pruinescence; with sparse fine setulae; in female, sternites 2-5 1.7 X broader than long, with elongated setae along posterior edges.

Male genitalia. Surstylus articulated with epandrium (Figs. 5C-D); tapering evenly through basal two-thirds, distal third thin, parallel-sided; abruptly curving ventromedially; distinct medial ridge through length; dorsally setose except distal quarter only with tiny hair-like setulae; dorsolateral surface densely pilose. Aedeagus (Figs. 5A-B) broad, with lateral third of distiphallus dorsoventrally flattened, wing-like; lateral edges with serrated teeth; posterior edge rounded, shovel-like; dorsally with large median ridge tapering to point at dorsalmost part. Hypandrium (Fig. 5A) as paired posteriorly-directed lateral lobes; with patch of small setulae distally; anterolateral edges pinched inwards. Paramere absent. Aedeagal apodeme normal, thick, branched posteriorly into 2 small arms; curvature such 
that ventral surface concave from lateral view. Ejaculatory apodeme distinct, similar in

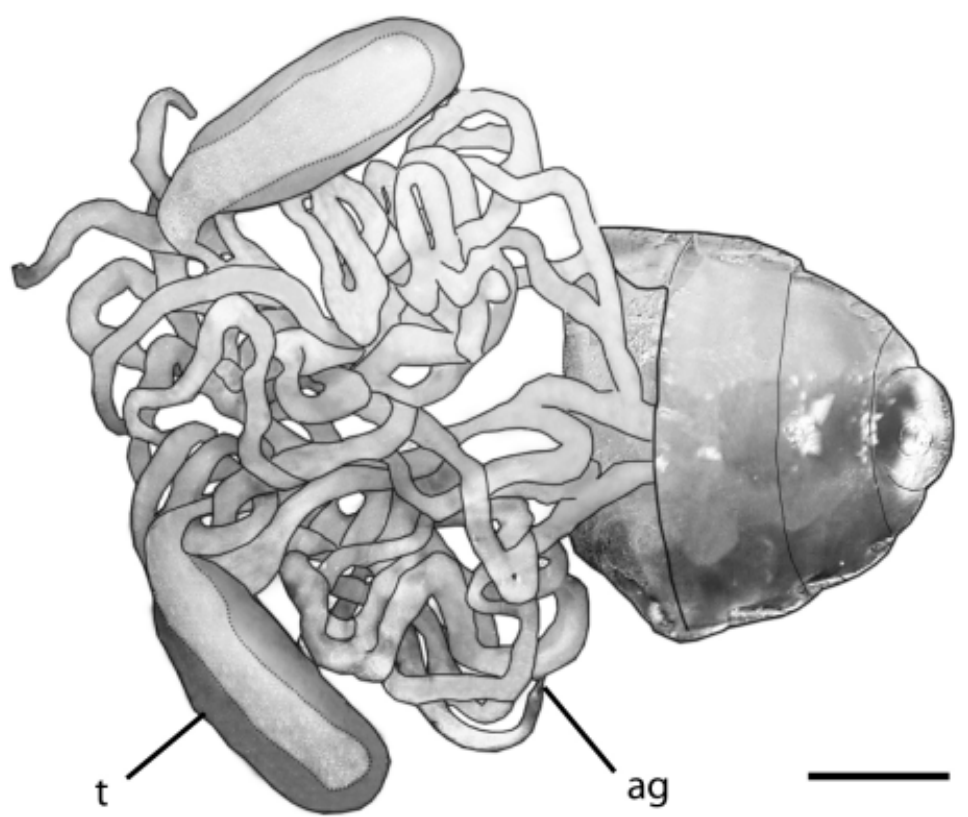

FIGURE 4. Evertomyia albeto, sp. nov. $0^{x}$. Accessory glands and testes, ventral view. Scale bar = $0.1 \mathrm{~mm} . \mathrm{ag}=$ accessory gland; $\mathrm{t}=$ testes.
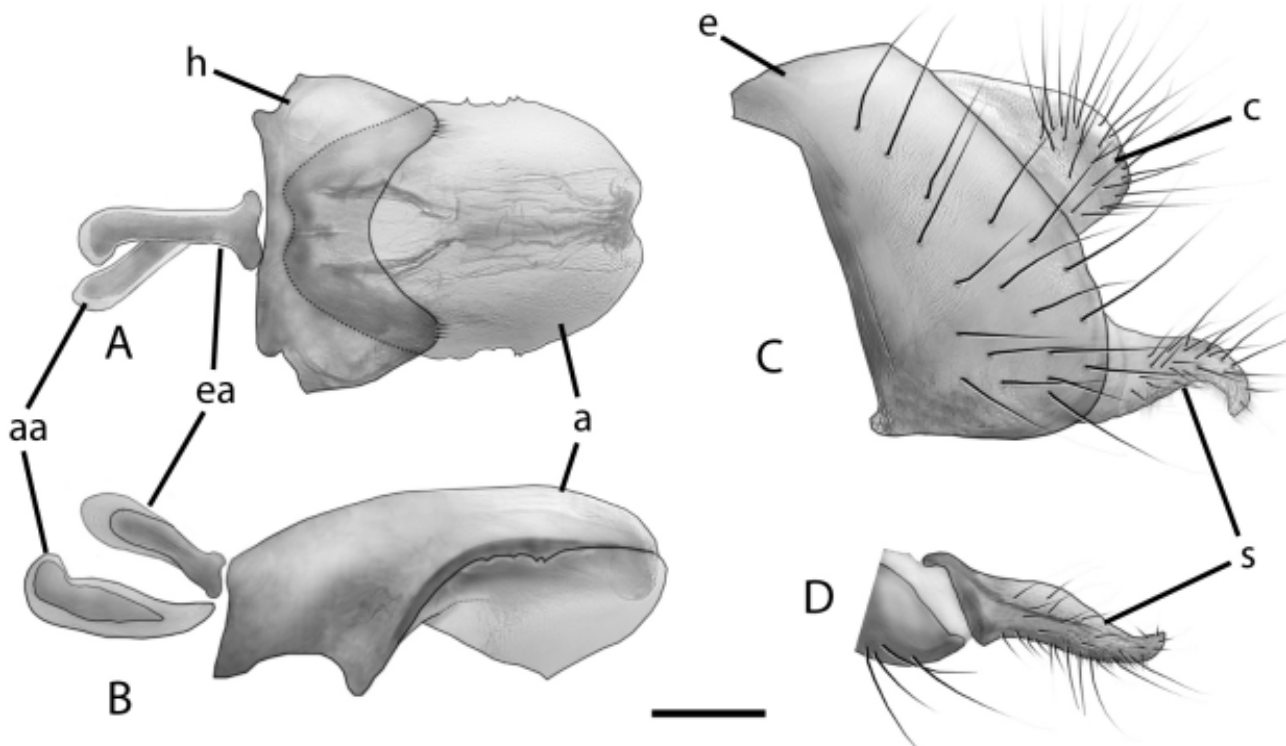

FIGURE 5. Evertomyia albeto, sp. nov. ${ }^{\star}$. Male genitalia. Scale bar $=0.2 \mathrm{~mm}$. A) Aedeagal complex, ventral view. B) Aedeagus, lateral view. C) Epandrial complex, lateral view. D) Surstylus, dorsal view. a=aedeagus, aa=aedeagal apodeme, $\mathrm{c}=$ cercus, e=epandrium, ea=ejaculatory apodeme, $\mathrm{h}=$ hypandrium, $\mathrm{s}=$ surstylus. 
Female terminalia. Sternite 8 (Figs. 6A-B) slightly longer than broad, parallel-sided but with edges pinched inwards in anterior part; entirely sclerotized, without lateral arms; paired central processes originating at mid-length of sternite 8 , greatly enlarged and broadened, extending slightly beyond posterior edge of sternite 8; lacking distal hooks; process setose. Tergite 8 with lateral edges extending into pilose lateral lobes along sides of sternite 8. Spermathecae (Figs. 6C-D) round; single spermatheca $0.14 \mathrm{~mm}$ diameter, paired $0.11 \mathrm{~mm}$ each; paired spermathecae each with elongated ducts beyond bifurcation (Fig. 6C); each with small external teeth sub-basally (Fig. 6D).

A

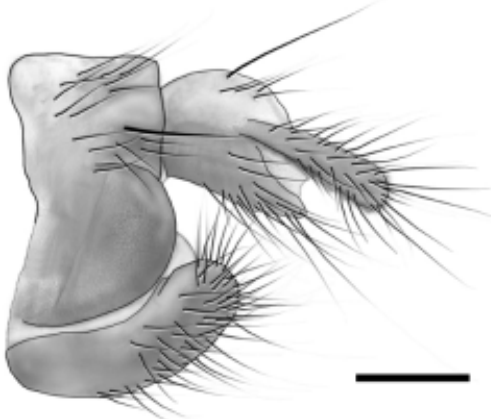

B

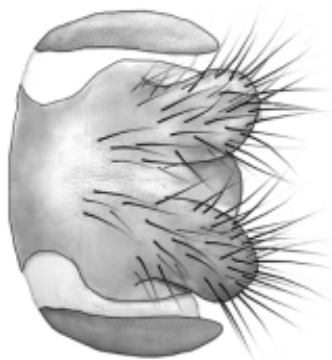

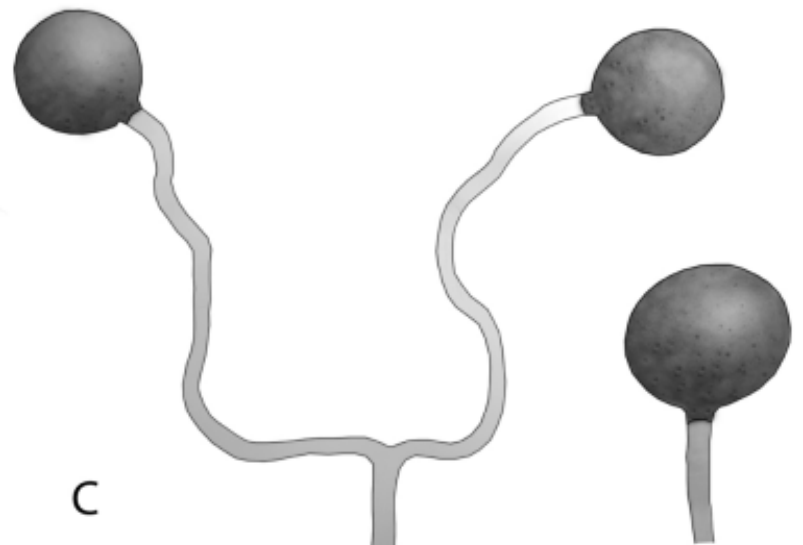

D

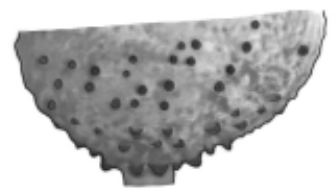

FIGURE 6. Evertomyia albeto, sp. nov. ㅇ. Female genitalia. Scale bar $=0.2 \mathrm{~mm}$. A) Terminalia, lateral view. B) Terminalia, ventral view. C) Spermathecae. D) Spermatheca (single), showing texture.

\section{Immatures. Unknown.}

Biology. Specimens of the this species have only been collected in January.

Type material. Holotype $o^{x}$ (double mounted on minuten, very good condition but some setae broken) deposited in MNHN with the following labels: "NOUVELLE CALEDONIE", "Muséum Paris / Mt. Humboldt / alt. 1350 m / 20/22. I. 1987 / R. et S. Tillier", "LAUXANIIDAE / S.D. Gaimari specimen / 01022" (orange label), "HOLOTYPUS / Evertomyia / albeto / Gaimari o"' (red label). Paratypes. (same collection data as holotype) Province Sud. Mont Humboldt, 1350 m (R. et S. Tillier), 20-21.I.1987 [4o*, 3 우 (dissections 915, 916: $\sigma^{\star}$, SDG 01011; ㅇ, SDG 01010)]. Paratypes deposited in MNHN and USNM. 
Distribution. Known only from the middle elevations (1350 m) of Mont Humboldt, in the southern part of New Caledonia.

\section{Evertomyia frankadelia, sp. nov.}

(Figs. 3B, 7A-E)

Etymology. Named for my parents, Frank ("frank-") and Adele ("-adelia") Gaimari, who have been very supportive for so many years. The epithet is not intended to be interpreted as Latinized, but rather the "-ia" ending was added for euphony.

Diagnosis. Like E. webbi, this species has weaker, divergent ocellar setae, the face lacks paired spots, the ptilinial suture and antennal groove are unmarked, the scutum and scutellum are orange, lacking vittae or silvery grey pruinescence, and the anepisternum is pale without dark marks, although in this species is covered with bronzy brown pruinescence. Like E. albeto and E. matilei, the antennal arista is pubescent. Like all species except $E$. albeto, the face lacks a median spot and the midtibia has 1 strong spur. Like $E$. helenae, this species has bronzy pruinescence on the fronto-orbital plate, but in this species the entire fronto-orbital plate is covered. Unlike all other species, the orbital setae are weak (relative to the vertical setae) with the anterior seta much smaller than the posterior and is located midway between the posterior seta and the lunule edge, the face is uniformly yellowish orange, and the anterior dorsocentral seta is closer to the middle seta than to the transverse suture. In the female: sternites $2-5$ are more than $3 \mathrm{X}$ broader than long; syntergosternite 7 has the lateral part extended anteriorly into a lobe; sternite 8 is elongated, with anteriorly-directed lateral arms, the paired central processes are elongated, each with a distal hook; the spermathecae each have internal lobes at the entrance to the spermathecal duct.

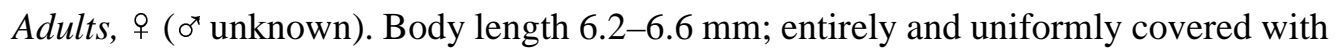
bronzy brown pruinescence, except as noted.

Head (Fig. 3B). 1.2-1.3 X higher than long, 1.5-1.7 X wider than high; eye slightly higher than long. Vertex with outer vertical seta slightly stronger than posterior orbital seta, inner seta 1.2-1.4 X longer. Ocellar setae weaker than anterior orbital seta; divergent. Postocellar setae as strong as posterior orbital seta. Frons with anterolateral part with pruinescence reduced and exposing orange ground color visible in profile below frontoorbital plate. Fronto-orbital plate with bronzy brown pruinescence fully present, not reduced. Orbital setae weak relative to vertical setae; posterior seta much stronger than anterior, 1.2-1.3 X longer; anterior seta arising midway between edge of lunule and posterior seta; anterior setae slightly closer together than posterior setae. Area surrounding antennal base slightly paler. Antennal 1 st flagellomere yellowish orange, 1.3-1.5 X longer than high; arista pubescent. Face yellowish orange, at slightly acute angle with frons; antennal grooves unmarked. Clypeus yellowish orange. Maxillary palpus yellowish orange, subcylindrical, slightly flattened; with black setulae. 
Thorax. Scutum 1.2-1.4 X longer than wide; scutellum with width at base 1.2-1.5 X greater than length. Distances between anterior and middle dorsocentral setae and between middle and posterior setae subequal or anterior to middle setae slightly less; anterior seta closer to middle seta than to transverse suture. Posterior pair of scutellar setae likely cruciate (no known specimens have these setae in their natural position). Legs. Brownish orange, except as noted. Forefemur slightly darker on posterodorsal surface; ctenidium as evenly spaced (each $0.26-0.32 \mathrm{~mm}$ apart) row of $8-10$ fine setulae; posterior surface with short row of small setae. Foretibia darkened apically. Midtibia darkened; with 1 strong spur. Wing. Length 5.5-6.1 mm; 2.7-2.9 X longer than high. Discal medial cell 4.7-5.1 X longer than crossvein dm-cu. Halter yellow with darkened knob.

Abdomen. Orange dorsally, with bronzy brown pruinescence laterally and along posterior edge of each segment; slightly shorter than scutum. Sternites bronzy brown pruinose; with sparse fine setulae; sternites 2-5 3.0-3.3 X broader than long, with slightly elongated setae along posterior edges. Syntergosternite 7 with lateral portion extended anteriorly.

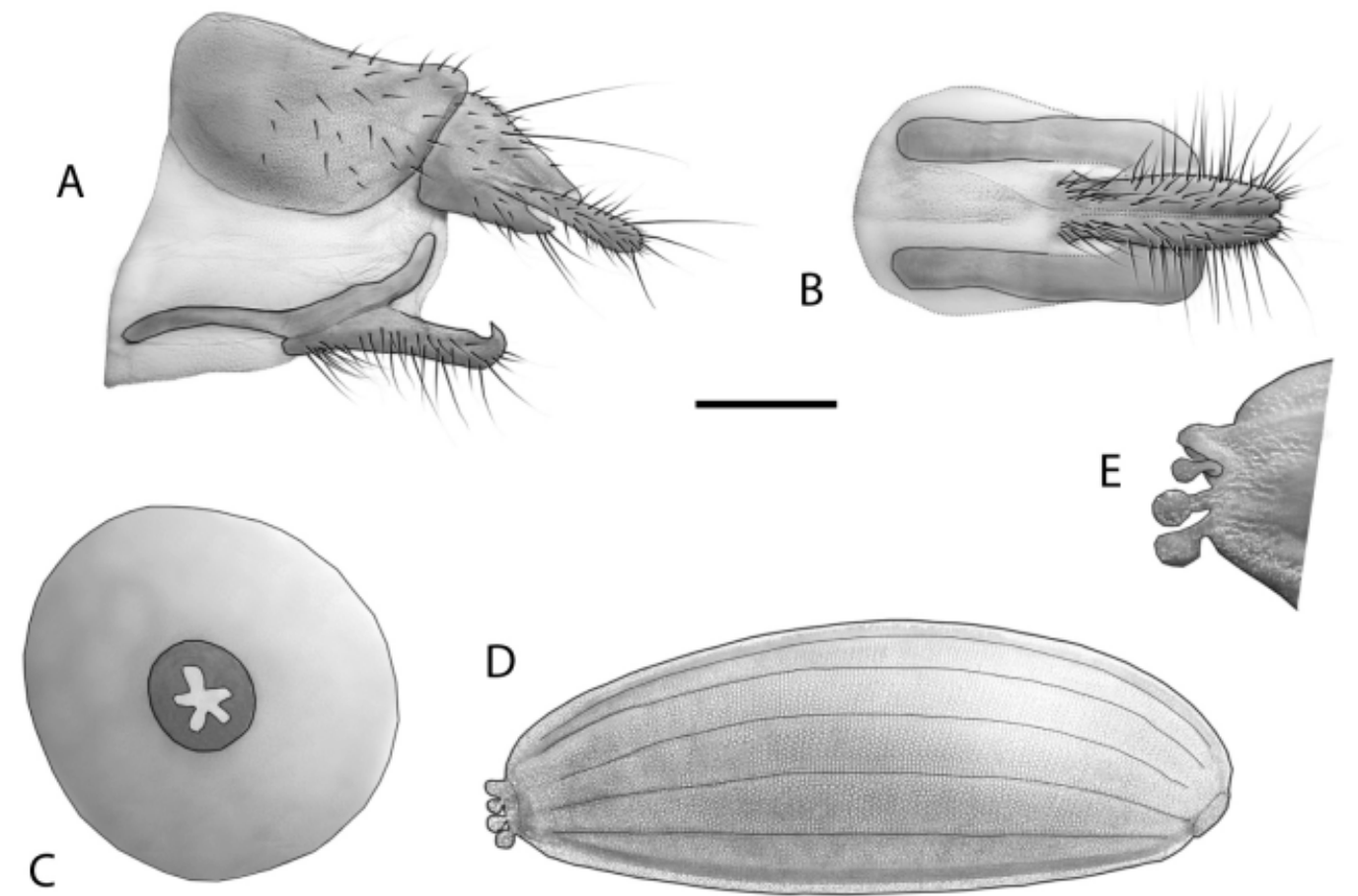

FIGURE 7. Evertomyia frankadelia, sp. nov. 우. Female genitalia and egg. Scale bar, A-B, \& D = $0.2 \mathrm{~mm} ; \mathrm{C}=0.05 \mathrm{~mm} ; \mathrm{E}=0.1 \mathrm{~mm}$. A) Terminalia, lateral view. B) Terminalia, ventral view. C) Spermatheca (single), cross section, top view looking into spermathecal duct opening. D) Egg, lateral view. E) Egg, eclosion end, lateral view.

Terminalia. Sternite 8 (Figs. 7A-B) elongate, width $0.6 \mathrm{X}$ length; parallel-sided; with only anteriorly-directed lateral arms sclerotized; paired central processes originating at 
mid-length of sternite 8 , elongate and extending slightly beyond posterior edge of sternite, thin, with medially-oriented distal hooks, process setose with basal patch of setae oriented posteroventrally. Spermathecae round; single spermatheca $0.13 \mathrm{~mm}$ diameter, paired 0.10 $\mathrm{mm}$ each; paired spermathecae on short stalks from bifurcation; each with distinct internal lobes at entrance from spermathecal duct (Fig. 7C).

Immatures. Egg (Fig. 7D). Micropylar end not protruding. Eclosion end with distinct lobes, 3 on each side (Fig. 7E).

Biology. Specimens of this species have been collected in the months from November through January. All known specimens were collected using Malaise traps across forest paths and along streams.

Type material. Holotype 우 (pinned, very good condition but with some moth scales) deposited in MNHN with the following labels: "NEW CALEDONIA / Rivière Bleue Prov[incial]. P[ar]k. / 35 km NW Yaté / 21 December 1991 / M.E. Irwin, D.W. Webb", "Malaise Trap / across forest / path", "HOLOTYPUS / Evertomyia / frankadelia / Gaimari १" (red label). Paratypes. Province Nord. Mont Mandjanié, 5.3 km WSW Puébo, $550 \mathrm{~m}$ (D. W. Webb), Malaise trap in tropical forest, 9-26.XI.1992 [1 9 (dissection 908: SDG 01007)]. Province Sud. Rivière Bleue Provincial Park: km 25.8 Riv. [= Rivière] Bleue road, $213 \mathrm{~m}$ (D.W. Webb, E. \& M. Schlinger), Malaise trap across forest path, 516.XI.1992 [1 ㅇ]; Parc 6, 150 m (L.B. de Larbogne, J. Chazeau, A. et S. Tillier), piège de Malaise [Malaise trap], forêt humide sur alluvions [humid forest on river bank], 520.I.1987 [1 ?]. Paratypes deposited in INHS and USNM.

Distribution. Known from the southern part of the island in the lower elevation (150$550 \mathrm{~m}$ ) rainforest of the Parc Provincial de la Rivière Bleue, and on Mont Mandjanié in the north.

\section{Evertomyia helenae, sp. nov.}

(Figs. 2, 3C, 8A-D, 9A-E)

Etymology. Named for my wife, Helen Greeley Gaimari, for all her love and support over the years.

Diagnosis. Like E. albeto, E. irwini, and E. matilei, this species has strong, proclinate, parallel-sided ocellar setae, at least a partially silvery grey pruinose fronto-orbital plate (for this species only anteriorly, forward of anterior orbital seta), and paired spots on the ventral part of the face. Like E. albeto and E. irwini, dorsocentral vittae are present, but in this species they are light bronzy pruinose. Like E. matilei and E. irwini, the ptilinial suture is dark brown to black pruinose only along the dorsal part terminating above the level of paired facial spots, and the antennal groove is distinctly marked from the dorsal part of the suture extending medially. Like E. matilei, the anepisternum has a dark brown spot at the base of the anepisternal seta, but in this species the remainder of the anepisterum is not fully greyish pruinose. Like E. matilei, E. irwini, and E. webbi, the anterior 
orbital seta is closer to the lunule edge than to the posterior seta. Like E. irwini and $E$. $w e b b i$, the arista is short plumose. Like all species except $E$. frankadelia, the orbital setae are strong with the posterior seta slightly stronger than the anterior seta, and the anterior dorsocentral seta is closer to the transverse suture than to the middle seta. Like all species except $E$. albeto, the face lacks a median spot and the midtibia has 1 strong spur. Unlike any other species, this species has a distinct dark stripe extending from the proepisternum through the posterior katepisternal seta. In the male: the surstylus is thick, setose, lacks pile, and the tip is bare and curves to a sharp medially hooked point; the aedeagus has its lateral edges bulging through its length, the ventral surface has a median longitudinal furrow; the hypandrium has a pair of very small posteriorly-directed median lobes; the paramere is absent.

Adults, ơ, 오. Body length 5.6-6.2 mm.

Head (Fig. 3C). 1.2-1.3 X higher than long, 1.4-1.5 X wider than high; eye as high as long. Vertex with light dusting of silvery grey pruinescence; outer vertical seta as strong as posterior orbital seta, inner seta 1.3-1.5 X longer. Ocellar triangle with darkened pruinescence relative to remainder of frons. Ocellar and postocellar setae strong; ocellar setae proclinate, parallel-sided. Occiput and median occipital sclerite yellowish, with light dusting of silvery grey pruinescence. Frons with anterolateral part with distinct black pruinose spot visible in profile below fronto-orbital plate. Fronto-orbital plate with silvery grey pruinescence only in anterior part, from anterior orbital seta forward; remainder of fronto-orbital plate light bronzy pruinose. Orbital setae strong; posterior seta 1.1-1.2 X longer than anterior; anterior seta arising slightly closer to edge of lunule than to posterior seta; distance between anterior setae subequal to that of posterior setae. Scape, facial carina, and area lateral to antennal base pale yellow, with light dusting of silver pruinescence. Antennal pedicel orange; 1st flagellomere dark brown, orange basally, 1.5-1.7 X longer than high; arista short plumose, with longest rays $0.8 \mathrm{~mm}$ and $0.4 \mathrm{X}$ height of 1st flagellomere. Face yellowish orange, with light dusting of silver pruinescence; antennal grooves with black pruinose area below antenna and along dorsal part of ptilinial suture; ventral part of face with paired dark brown pruinose spots. Parafacial, gena, and postgena pale yellow with light covering of silver pruinescence; dark brown spot below eye. Clypeus brownish. Maxillary palpus dark brown, nearly black; subcylindrical; with black setulae.

Thorax. Scutum (Fig. 2) 1.2-1.4 X longer than wide; scutellum (Fig. 2) with width at base 1.1-1.4 X greater than length; scutum and scutellum orange; narrow light bronzy pruinose dorsocentral vittae present (width of vitta = quarter width of area between vittae); some specimens with thin, slightly lighter median longitudinal line; scutellum with silvery grey pruinescence along lateral edge, with posterior edge pale yellow from posterior view; dorsal part of postpronotal lobe through notopleuron to wing base yellow pruinose, ventral part of postpronotal lobe dark brown pruinose. Anepisternum mostly pale, with dark brown spot at base of anepisternal seta and in anterodorsal part; distinct dark brown stripe from anterior part of proepisternum through posterior katepisternal seta. Distance between 
dorsocentral setae subequal, with anterior seta closer to transverse suture than to middle seta. Legs. Yellowish orange, except as noted. Coxae yellow, with light dusting of silvery white pruinescence. Forefemur with patch of silvery brown pruinescence on anterodorsal surface; ctenidium as evenly spaced (each $0.23-0.27 \mathrm{~mm}$ apart) row of 10-11 setulae; posterior surface with short row of small setae. Foretibia with brown bands basally and apically, with lighter band sub-basally. Midfemur with brown spot at midpoint on ventral surface. Midtibia with brown bands basally, sub-basally, and apically. Hindfemur with brown pruinose band on anterior and anteroventral surfaces beyond middle and apically. Hindtibia with silvery brown bands sub-basally (corresponding in position with band on femur) and apically; with 1 strong spur. Wing. Length 5.1-6.1 mm; 2.5-2.7 X longer than high. Discal medial cell 3.3-3.6 X longer than crossvein dm-cu. Halter yellow.

Abdomen. Yellowish orange; slightly shorter than scutum. Transverse rows of long setae along posterior edges of tergites becoming longer and stronger laterally. Lateral portion of tergite 1 (as part of syntergite $1+2$ ) with dark silvery grey pruinose patch; lateral portions of tergites 2-5 each with small brown spot visible from ventral view near tergal edge, and another small brown spot visible from dorsal view (both spots visible from lateral view). Sternites yellow with dusting of silvery white pruinescence; with sparse fine setulae, some along posterior edges slightly stronger; in female, sternites $2-52.1 \mathrm{X}$ broader than long, with elongate setae along posterior edge.
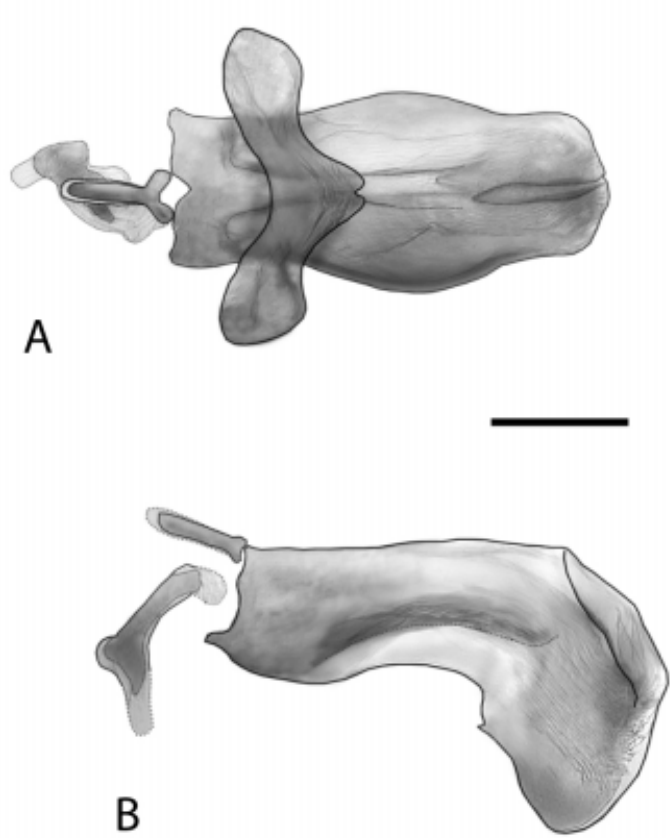

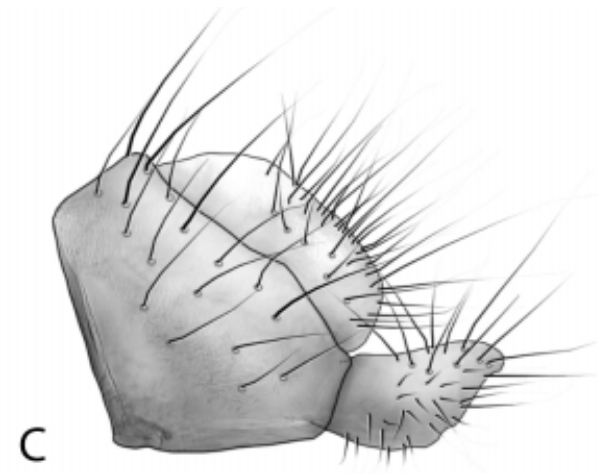

D

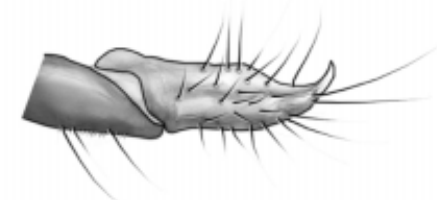

FIGURE 8. Evertomyia helenae, sp. nov. o ${ }^{\star}$. Male genitalia. Scale bar $=0.2 \mathrm{~mm}$. A) Aedeagal complex, ventral view. B) Aedeagus, lateral view. C) Epandrial complex, lateral view. D) Surstylus, dorsal view. 
Male genitalia. Surstylus articulated with epandrium (Figs. 8C-D); thickened, slightly tapering; tip bare, abruptly tapering and curving to sharp medially hooked point (Fig. 8D); setose, lacking pile. Aedeagus (Figs. 8A-B) with anterior and posterior ends subequal in width, but lateral edges evenly bulging through length; ventral surface with median longitudinal furrow to gonopore; dorsally with large median ridge. Hypandrium (Fig. 8A) a thin curved band with pair of very small, posteriorly-directed median lobes. Paramere absent. Aedeagal apodeme minute, thin, branched posteriorly into 2 arms, appearing as "Y"; straight from lateral view. Ejaculatory apodeme larger that aedeagal apodeme.

Female terminalia. Sternite 8 (Figs. 9A-B) nearly as long as broad; sides slightly tapering posteriorly; heavily sclerotized along saddle-shaped posterior edge and along paired anterior patches; paired central processes not separated from sternite; dorsally flattened with stiff dorsally directed setae. Paired, heavily sclerotized accessory structures (Fig. 9C) at interface between hypoproct and sternite 8 (Figs. 9A). Tergite 8 lightly sclerotized, apparently lacking lobes. Spermathecae (Fig. 9D) round, small; single spermatheca $0.09 \mathrm{~mm}$ diameter, paired $0.075 \mathrm{~mm}$ each; paired spermathecae on short stalks after bifurcation.
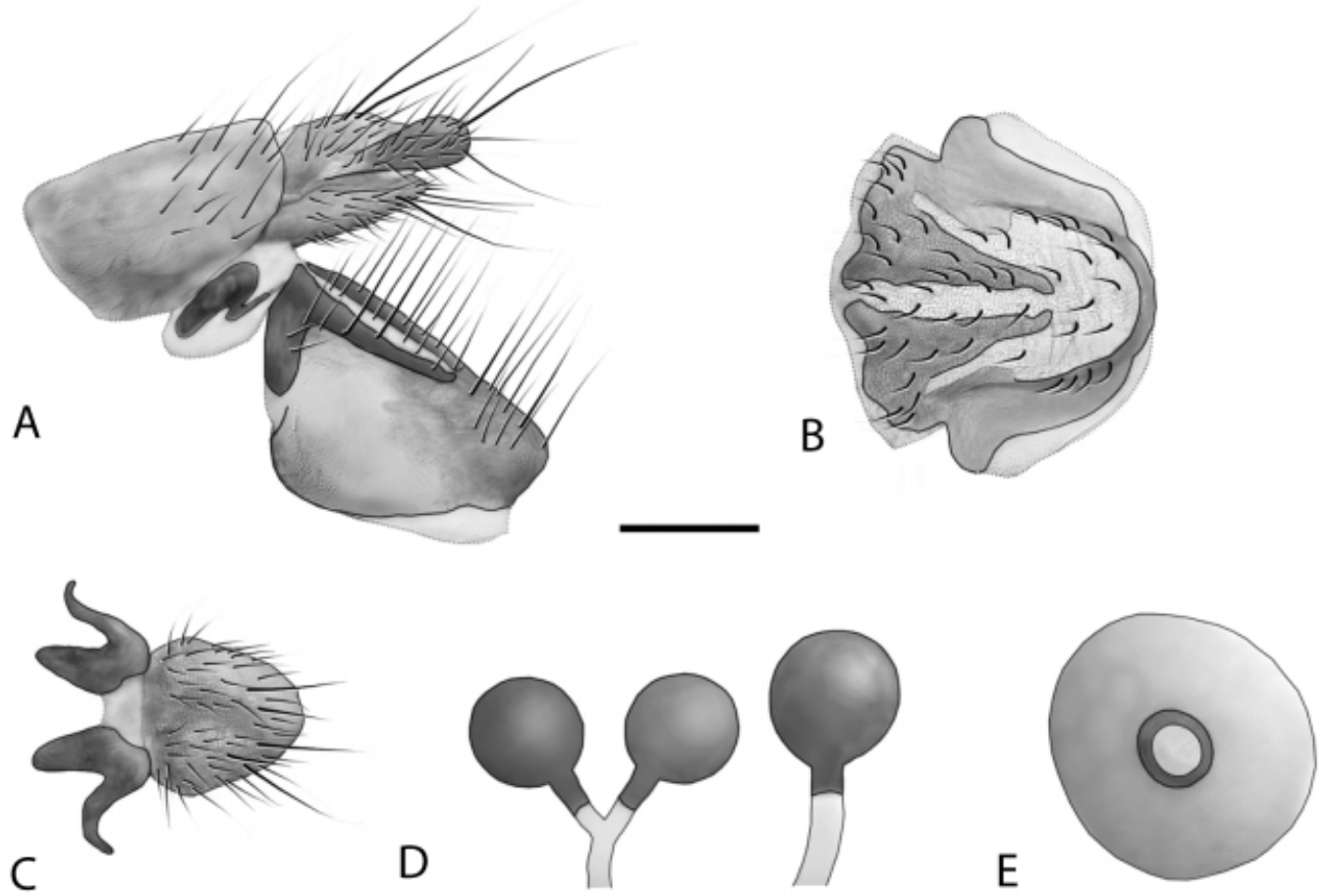

FIGURE 9. Evertomyia helenae, sp. nov. 우. Female genitalia. Scale bar, A-C = $0.2 \mathrm{~mm}$; D = 0.1 $\mathrm{mm} ; \mathrm{E}=0.05 \mathrm{~mm}$. A) Terminalia, lateral view. B) Terminalia, ventral view. C) Terminalia, accessory structures, ventral view. D) Spermathecae. E) Spermatheca (single), cross section, top view looking into spermathecal duct opening. 
Immatures. Unknown.

Biology. Specimens of this species have been collected in all months from October through January. Several were attracted to a feces trap, and several were collected using Malaise traps across forest paths.

Type material. Holotype $\sigma^{x}$ (glued to paper point, very good condition) deposited in MNHN with the following labels: "N. CALÉDONIE / Mt. Panié; 300m / feces trap; 12- / xii-1990; Bickel", "HOLOTYPUS / Evertomyia / helenae / Gaimari ơ" (red label). Paratypes. Province Nord. Headwaters of Houailou R[iver]. (C.R. Joyce), 26.X.1958 [10 $0^{x}$. (same collection data as holotype) Mount Panié, $300 \mathrm{~m}$ (D. Bickel), feces trap, 12.XII.1990 [5우 (dissection 917: SDG 01018)]. Yiambi [Yambé], NE, 500-700 m (J. \& M. Sedlacek), 14.X.1967 [1 ㅇ]. Province Sud. Rivière Bleue Provincial Park: 30 km NW

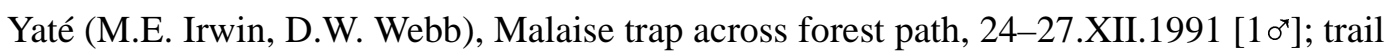
to Vallée de Pourina, $850 \mathrm{~m}$ (D.W. Webb), Malaise trap across forest path, 19-28.XI.1992 [20 (dissection 910: SDG 01009)]. Mont Koghi, 450-600 m (J. \& M. Sedlacek), 4-

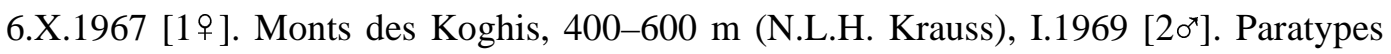
deposited in AMSA, BPBM, INHS, MNHN, and USNM.

Distribution. Known only from the rainforests in the low to middle elevations of the Monts des Koghis and Rivière Bleue Provincial Park in southern New Caledonia, and of Mount Panié, the Yambé vicinity, and along the headwaters of the Houailou River in the north.

\section{Evertomyia irwini, sp. nov.}

(Figs. 1, 10A-E, 11A-C)

Etymology. Named for my good friend and mentor, Dr. Michael E. Irwin, who was one of the collectors of this and other species of this genus.

Diagnosis. Like E. albeto, E. helenae, and E. matilei, this species has strong, proclinate, parallel-sided ocellar setae, silvery grey pruinescence on the fronto-orbital plate (although unlike E. helenae, this pruinescence covers it entirely), and paired spots on the ventral part of the face. Like E. albeto, silvery grey dorsocentral vittae are present but are narrower than that species, with a width equal to one-fifth the distance between vittae; and vittae extend through the scutellum, but unlike that species they extend only along the lateral edge, and the posterior edge is pale yellow from posterior view. Like E. helenae and E. matilei, the ptilinial suture is dark brown to black pruinose only along the dorsal part terminating above the level of paired facial spots, and the antennal groove has a distinct dark brown to black mark extending medially from the dorsal part of this suture. Like $E$. helenae, E. matilei, and E. webbi, the anterior orbital seta is closer to the lunule edge than to the posterior seta. Like E. helenae and E. webbi, the antennal arista is short plumose. Like all species except $E$. frankadelia, the orbital setae are strong with the posterior seta slightly stronger than the anterior seta, and the anterior dorsocentral seta is closer to the 
transverse suture than to the middle seta. Like all species except $E$. albeto, the face lacks a median spot and the midtibia has 1 strong spur. In the male: sternites $2-5$ are $2 \mathrm{X}$ wider than long; the surstylus is long and strap-like, gradually curved medially, with the outer surface setose and pilose, the inner surface is bare, and the tip is bare and curving to a sharp medially hooked point; the aedeagus is slightly tapered distally, the ventral surface has paired ridges forming a median furrow; the hypandrium is a broad band with the anterior and posterior edges parallel, with 1-2 small setulae posterolaterally; the paramere is present, tusk-like, and curved outwards, with 1 small setula at the base beside the hypandrial setula. In the female: sternites $2-5$ are $2-3 X$ wider than long; syntergosternite 7 has a longitudinal dark mark lateral of the spiracle; sternite 8 is as wide as long, with posteriorly-directed lateral arms and an anteriorly-directed medial extension, and the paired central processes are slightly elongated, lacking a distal hook.

Adults, ơ , ․ . Body (Fig. 1) length 5.7-6.8 mm.

Head (Fig. 3D). 1.1-1.3 X higher than long, 1.4-1.7 X wider than high; eye as high as long. Vertex with light dusting of silvery grey pruinescence; outer vertical seta as strong as posterior orbital seta, inner seta 1.4-1.5 X longer. Ocellar triangle covered with same silvery grey pruinescence as vertex. Ocellar setae strong; proclinate, parallel-sided. Postocellar setae strong, nearly as strong as ocellar setae. Occiput and median occipital sclerite orange, with light dusting of silvery grey pruinescence. Frons with anterolateral part with brown pruinose spot visible in profile below fronto-orbital plate. Fronto-orbital plate densely covered with silvery grey pruinescence. Orbital setae strong; posterior seta 1.0 $1.2 \mathrm{X}$ longer than anterior; anterior seta arising slightly closer to edge of lunule than to posterior seta; distance between anterior setae subequal to that of posterior setae. Antennal scape, facial carina, and area lateral to antennal base pale yellow, with light dusting of silver pruinescence. Antennal pedicel and 1st flagellomere orange; 1st flagellomere 1.3-1.4 $\mathrm{X}$ longer than high; arista short plumose, with longest rays $0.7-1.1 \mathrm{~mm}$ and $0.4-0.6 \mathrm{X}$ height of 1st flagellomere. Face yellowish orange, with light dusting of silver pruinescence; antennal grooves with dark brown to black pruinose area below antenna and along dorsal part of ptilinial suture; ventral part of face with paired dark brown pruinose spots. Parafacial, gena, and postgena yellowish orange with light covering of silver pruinescence. Clypeus yellowish orange. Maxillary palpus dark orange, darkening distally, darkest at tip; subcylindrical; with black setulae.

Thorax. Scutum 1.1-1.3 X longer than wide; scutellum with width at base 1.2-1.4 X greater than length; scutum and scutellum orange; narrow silvery grey dorsocentral vittae present (width of vitta $=$ one-fifth width of orange area between vittae), extending through scutellum along lateral edge; some specimens with thin, slightly lighter median longitudinal line; posterior edge pale yellow from posterior view; postpronotal lobe through notopleuron to wing base yellow pruinose. Dorsal three-quarters of anepisternum and stripe through katepisternal setae orange, as on scutum; remainder of pleural area pale silvery yellow pruinose. Distance between dorsocentral setae subequal, with anterior seta 
closer to transverse suture than to middle seta. Legs. Yellowish orange, except as noted. Coxae yellow, with light dusting of silvery white pruinescence. Forefemur with patch of silvery brown pruinescence on anterodorsal surface; ctenidium as evenly spaced (each $0.25-0.33 \mathrm{~mm}$ apart) row of 9-12 setulae; posterior surface with short row of small setae. Foretibia with brown bands sub-basally and apically. Midfemur with brown spot at midpoint, on ventral surface. Midtibia with brown bands basally, sub-basally, and apically. Hindfemur with brown pruinose band on anterior and anteroventral surfaces beyond middle and apically. Hindtibia with silvery brown bands sub-basally (corresponding in position with band on femur) and apically; with 1 strong spur. Wing. Length 5.2-6.2 mm; 2.5$2.8 \mathrm{X}$ longer than high. Discal medial cell 4.0-4.4 X longer than crossvein dm-cu. Halter yellow.

Abdomen. Yellowish orange; slightly shorter than scutum. Transverse rows of long setae along posterior edges of tergites becoming longer and stronger laterally. Lateral portion of tergite 1 (as part of syntergite $1+2$ ) with dark silvery grey pruinose patch; lateral portions of tergites 2-5 silvery white pruinose, with brown spot visible from ventral view near tergal edge, and another brown spot visible from dorsal view (both spots visible from lateral view (Fig. 1)). Sternites yellow with dusting of silvery white pruinescence; with sparse fine setulae; in male, sternites 2-5 $2 \mathrm{X}$ wider than long; in female, sternites 2-5 2.4 $\mathrm{X}$ wider than long, with elongated setae along posterior edges. In female, syntergosternite 7 with dark longitudinal mark lateral of spiracle.

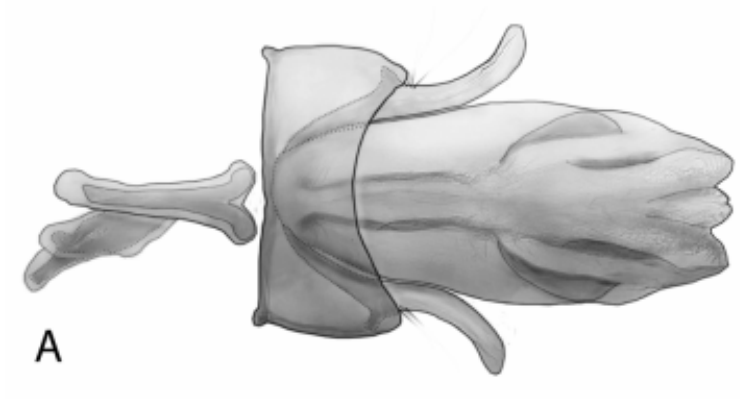

D
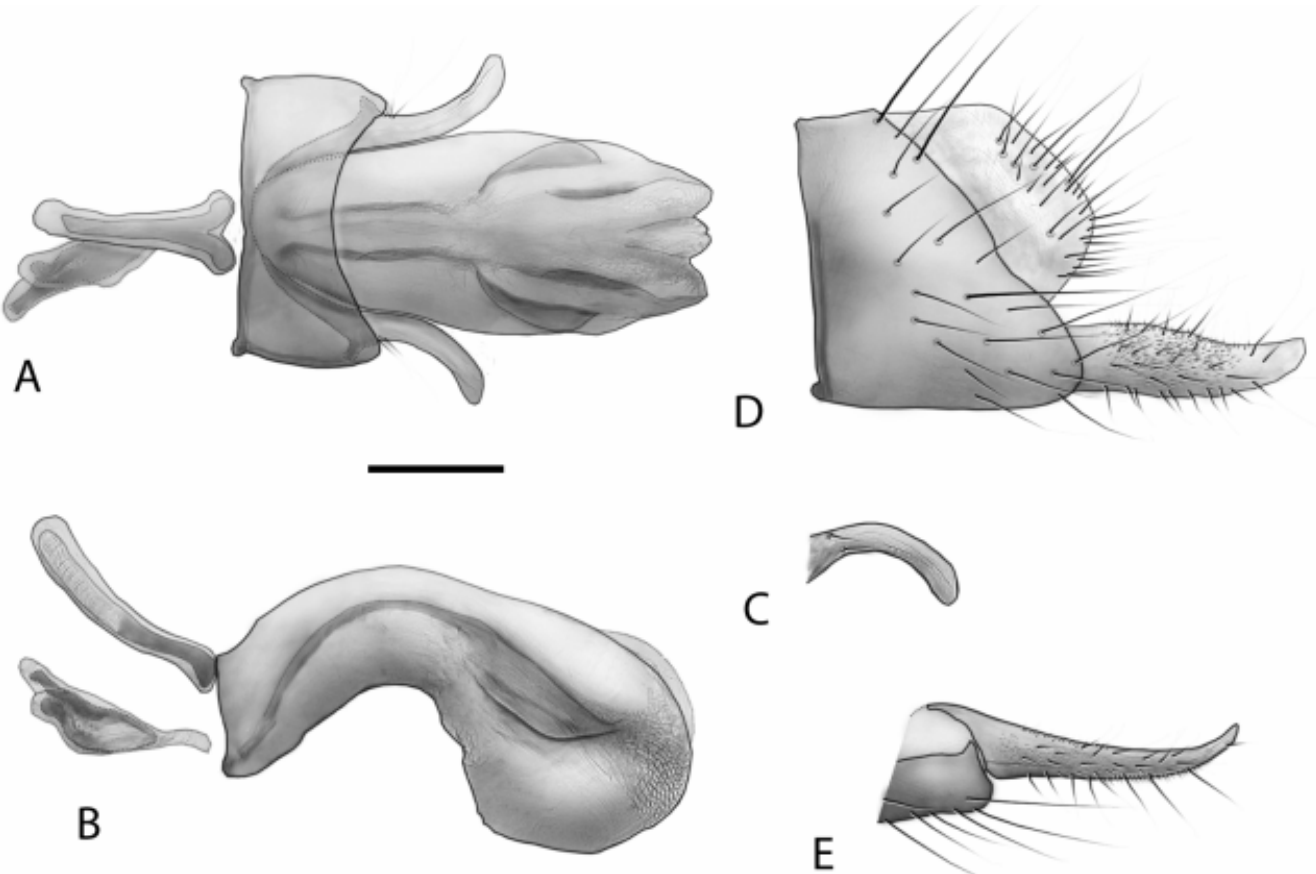

FIGURE 10. Evertomyia irwini, sp. nov. ${ }^{\star}$. Male genitalia. Scale bar $=0.2 \mathrm{~mm}$. A) Aedeagal complex, ventral view. B) Aedeagus, lateral view. C) Paramere, lateral view. D) Epandrial complex, lateral view. D) Surstylus, dorsal view. 
Male genitalia. Surstylus articulated with epandrium (Figs. 10D-E); long, strap-like, gradually curved medially and tapering distally; outer surface setose and densely pilose, inner surface bare; tip bare except for few tiny hair-like setulae; curving to sharp medially hooked point. Aedeagus (Figs. 10A-B) evenly thickening through basal two-thirds, then tapering slightly distally; ventral surface with paired wing-like ridges forming median longitudinal furrow; dorsally with median longitudinal ridge. Hypandrium (Fig. 10A) a broad band with anterior and posterior edges parallel; posterolaterally with 1 small setula. Paramere (Figs. 10A, C) present, tusk-like, curved outwards; with 1-2 small setulae at base beside hypandrial setula. Aedeagal apodeme normal, thick; branched posteriorly into 2 arms, appearing as "Y" with posterior tips enlarged; curvature such that ventral surface concave from lateral view. Ejaculatory apodeme subequal; bilobed anteriorly.

Female terminalia. Sternite 8 (Figs. 11A-B) as broad as long, parallel-sided; with only posteriorly-directed lateral arms and small anteriorly-oriented medial extension sclerotized, posterior half of each lateral arm most darkly sclerotized; paired central processes originating at anterior base of sternite 8 , short (but longer than wide) and ending before posterior edge of sternite, lacking distal hooks; process medially fused through basal twothirds, setose. Spermathecae round; single spermatheca $0.12 \mathrm{~mm}$ diameter, paired 0.09 $\mathrm{mm}$ each; paired spermathecae on short stalks after bifurcation.

Immatures. Egg. Micropylar end enlarged, globose (Fig. 11C). Eclosion end with distinct lobes, 3 on each side.

A
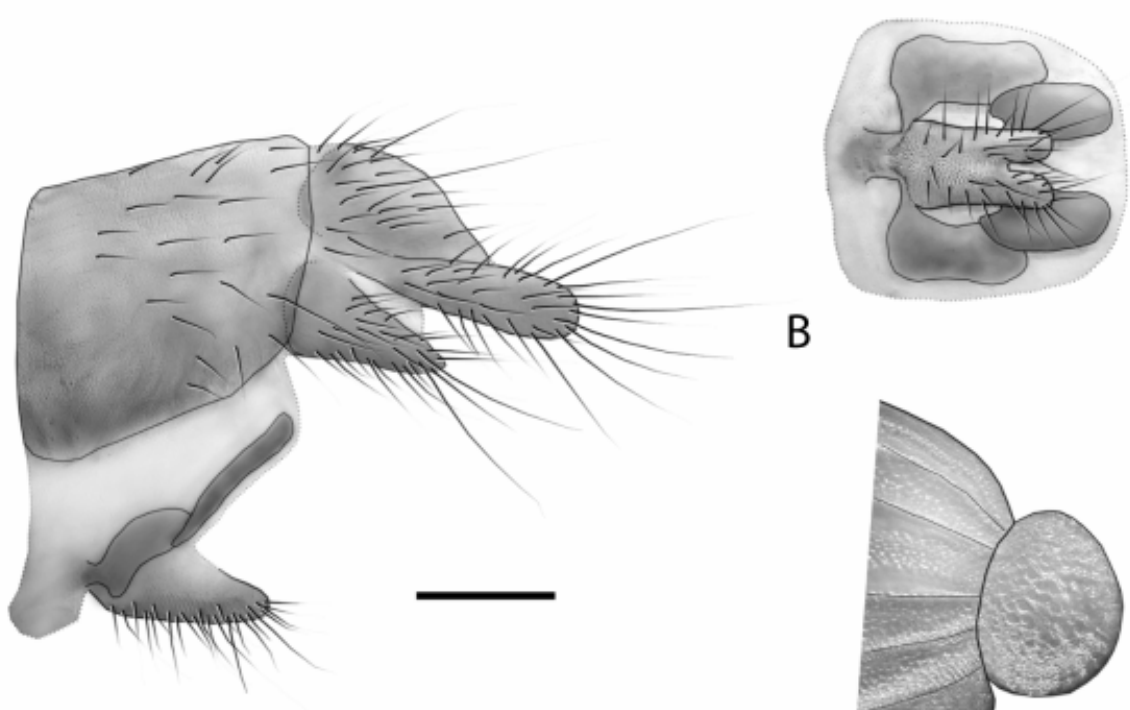

B

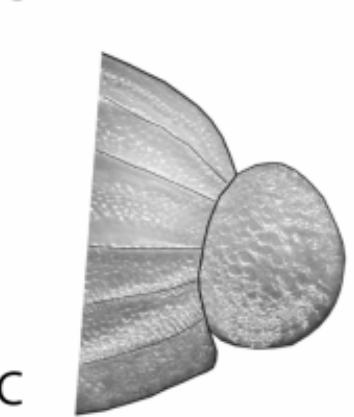

FIGURE 11. Evertomyia irwini, sp. nov. ㅇ. . Female genitalia and egg. Scale bar, A-B $=0.2 \mathrm{~mm} ; \mathrm{C}$ $=0.1 \mathrm{~mm}$. A) Terminalia, lateral view. B) Terminalia, ventral view. C) Egg, micropylar end, lateral view. 
Biology. Specimens of this species have been collected in all months from August through March, except September. This species is attracted to human feces and wallaby dung, but has been most commonly collected using Malaise traps, often across forest paths and along streams.

Type material. Holotype $o^{x}$ (pinned, very good condition) deposited in MNHN with the following labels: "NEW CALEDONIA / Mt. Khogis, 500 m / 17 km NNE Nouméa / 22 December 1991 / M.E. Irwin, D.W. Webb", "Malaise Trap / across forest / stream", "HOLOTYPUS / Evertomyia / irwini / Gaimari o" (red label). Paratypes. Province Nord. 13 km SE Kaala-Gomén, 2046'07"S, 164²7'26"E, 100 m (M.E. Irwin, D.W. Webb),

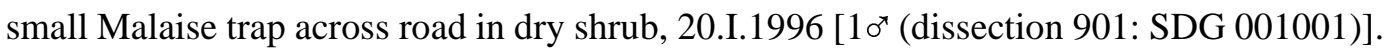
Pouebo, 100 m (R. Straatman), Malaise trap, 27.I.1964 [19]. Province Sud. Between Plum \& Yati [Yaté] (T. C. Maa), 25.III.1968 [1ㅇ․ Col d'Amieu, Rte. [= Route] Canala

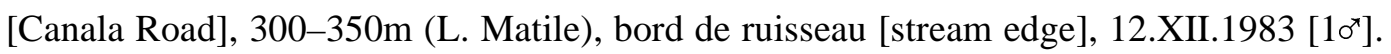
Mont Dore (north side), 4 km NW Plum (M.E. Irwin, D.W. Webb), Malaise trap in dry wash with pools, 19.XII.1991 [1우. Mont Dzumac road, 22 ${ }^{\circ} 03^{\prime} \mathrm{S}$ x $166^{\circ} 28^{\prime} \mathrm{E}, 700 \mathrm{~m}$ (G.B. Monteith), human dung trap, site 8737, 31.X-1.XI.2001 [1우. Mt. Koghi: 380 m (J.L. Gressitt \& T.C. Maa), light trap, 18.III.1968 [1 ơ] $^{\star}$ 400-600 m (N.L.H. Krauss), II.1973 [1 o $^{x}$; 500 m (J. \& M. Sedlacek), 27.X.1967 [1 o $^{x}$, (M. Sedlacek), 23-27.VIII.1967 [1 o, $^{x}$ 1우, (R. Straatman), 28.XI.1963 [1이, 29.XI.1963 [1 $\circ^{x}$ ], (R. Straatman), Malaise trap,

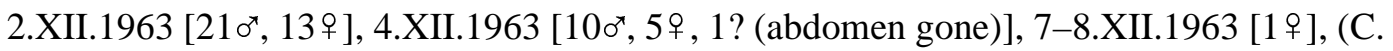
Yoshimoto \& N. Krauss), Malaise trap, 26-30.I.1963 [47 ${ }^{\star}$, 4ㅇ]; 500-550 m (N.L.H.

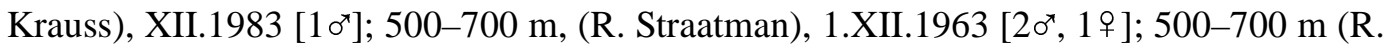
Straatman), Malaise trap, 1.XII.1963 [7 $\circ^{*}, 4$ 우]; 500-750 m (J. \& M. Sedlacek), 25-

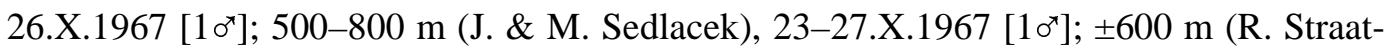

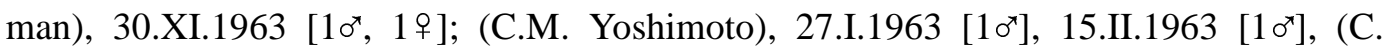
Yoshimoto \& N. Krauss), Malaise trap, 27.I.1963 [4 $\left.\circ^{x}\right]$, (N.L.H. Krauss), 28.I.1962 [1 $\left.0^{x}\right]$,

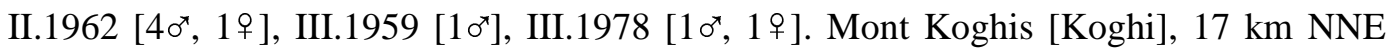
Nouméa: 22¹0'34"S, 166³0'17"E, 425 m (M.E. Irwin, D.W. Webb, E. I. Schlinger), Malaise trap across path in rainforest, 8-10.I.1996 [2 ○$\left.^{x}\right], 10-11 . I .1996$ [1 $\left.0^{x}\right], 22-24 . I .1996$

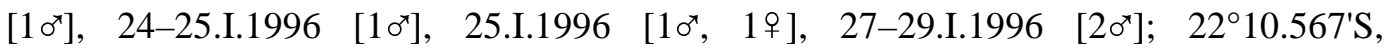

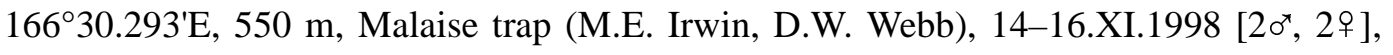
18.XI.1998 [1 $\circ^{\star}, 1$ 우]; 350 m (M.E. Irwin, D.W. Webb), Malaise trap, 26.XII.1991 [1 우; $500 \mathrm{~m}$ (M.E. Irwin, D.W. Webb), Malaise trap in tropical forest, 30-31.X.1992 [80 , 4 우 (dissection 902: $\sigma^{x}$, SDG 01002)], (D.W. Webb), Malaise trap in tropical forest, 515.XI.1992 [1 $0^{x}, 1$ ㅇ]; (same collection data as holotype) $500 \mathrm{~m}$ (M.E. Irwin, D.W. Webb),

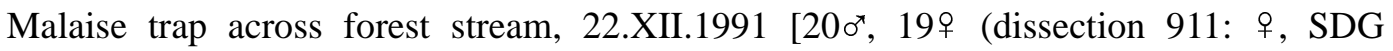

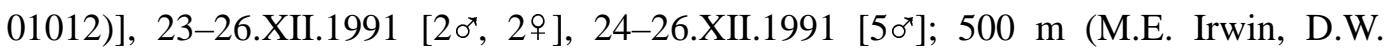

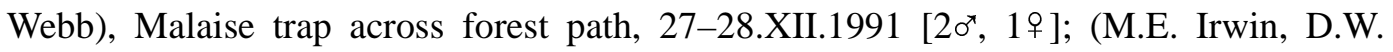
Webb), Malaise trap across forest stream, 27-28.XII.1991 [1 $\circ^{\star}, 1$ ㅇ]; $22^{\circ} 11^{\prime} \mathrm{S}$ x $166^{\circ} 01^{\prime} \mathrm{E}$, $500 \mathrm{~m}$ (G.B. Monteith), Wallaby dung trap, site 8914, 26-27.I.2002 [3 ơ] $^{{ }^{7}}$ 28-29.XI.2001 
[1ㅇ]. Monts des Koghis, 200-400 m (N.L.H. Krauss), I.1969 [1 $\left.10^{\star}\right], 400-600$ m (N.L.H.

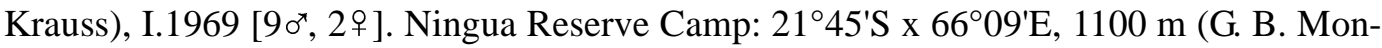
teith), human dung trap, site 8640, 12-14.XI.2001 [20`]. Plaine des Lacs area (C.R. Joyce),

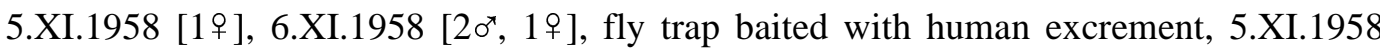

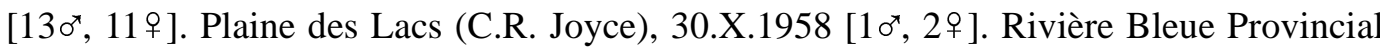
Park: 212 m (E. \& M. Schlinger, D.W. Webb), 20-28.XI.1992 [10`]; 30 km NW Yaté, 270 m (M.E. Irwin, D.W. Webb), 27.XII.1991 [20*, 1ㅇ], 550 m, (M.E. Irwin, D.W. Webb), Malaise trap across forest path, 27-28.XII.1991 [20*, 1ㅇ]; $35 \mathrm{~km}$ NW Yaté (M.E. Irwin,

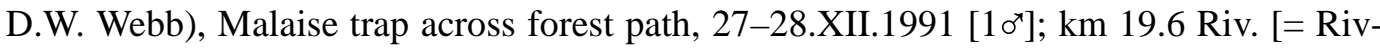
ière] Bleue road, $183 \mathrm{~m}$ (D.W. Webb), Malaise trap across forest path, 20-28.XI.1992 [20']; km 25.8 Riv. [= Rivière] Bleue road, 213 m (M.E. Irwin, D.W. Webb), Malaise trap across forest path, 3-5.XI.1992 [1 ơ]; Parc 6, 150 m (L.B. de Larbogne, J. Chazeau, A. et S. Tillier), piège de Malaise [Malaise trap], forêt humide sur alluvions [humid forest on river bank], 5-20.I.1987 [1 ơ] $^{\star}$ Parc 7, 170 m (L.B de Larbogne, J. Chazeau), forêt humide sur pente [humid forest on slope], 19.XI-4.XII.1985 [7 $0^{\star}, 3$ 우 (dissection 909: ${ }^{\star}$, SDG 01008)]; Pic du Grand Kauri, 22 ${ }^{\circ} 17^{\prime} \mathrm{S}$ x $166^{\circ} 54^{\prime} \mathrm{E}, 250 \mathrm{~m}$ (G. B. Monteith), human dung trap, site 8704, 20-21.XI.2001 [2우 QMBA]; Pic du Pin, east base, $22^{\circ} 15^{\prime} \mathrm{S} \times 166^{\circ} 49^{\prime} \mathrm{E}$,

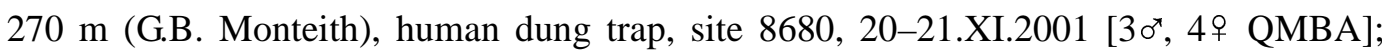
Pont Germain, $22^{\circ} 06^{\prime} \mathrm{S}$ x $166^{\circ} 39^{\prime} \mathrm{E}, 160 \mathrm{~m}$ (G. B. Monteith), human dung trap, site 8724,

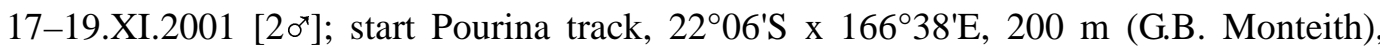

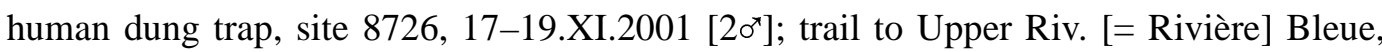
$290 \mathrm{~m}$ (D.W. Webb), Malaise trap across forest path, 3-5.XI.1992 [1 ㅇ], 5-16.XI.1992 [60, 3 우 (dissection 903: 오, SDG 01003)]; trail to Vallée de Pourina, $850 \mathrm{~m}$ (D.W. Webb), Malaise trap across forest path, 19-28.XI.1992 [1 $\left.0^{\star}, 2 \circ\right]$. Paratypes deposited in AMNH, AMSA, ANIC, BMNH, BPBM, CASC, CAUC, CNCI, CSCA, DEBU, EMEC, HNHM, INHS, KUEC, MCZC, MHNG, MNHN, MZSP, NHMW, NMSA, QMBA, UCDC, USNM, ZISP, ZMHB, and ZMUC.

Distribution. Found in both the Province Nord and Province Sud. In the north, found only at the low elevations $(100 \mathrm{~m})$ near Kaala-Gomén and Pouebo. Considerably more widespread in the south, including the low to middle elevation rainforests of Col d'Amieu, Mont Dore, Mont Dzumac, the Monts des Koghis, Mont Ningua, the Plan des Lacs vicinity, the Yaté vicinity, and the Parc Provincial de la Rivière Bleue.

\section{Evertomyia matilei, sp. nov.}

(Figs. 3E, 12A-D, 13A-D)

Etymology. Named for Dr. Loïc Matile, the late curator of Diptera at MNHN.

Diagnosis. Like E. albeto, E. helenae, and E. irwini, this species has strong, proclinate, parallel-sided ocellar setae, silvery grey pruinescence on the fronto-orbital plate (although unlike E. helenae, this pruinescence covers it entirely), and paired spots on the 
ventral part of the face, but unlike these species, the entire dorsal part of the scutum is silvery grey pruinose, as is the scutellum. Like E. albeto and E. frankadelia, the antennal arista is pubescent. Like E. helenae and E. irwini, the ptilinial suture is dark brown to black pruinose only along the dorsal part terminating above the level of paired facial spots, and the antennal groove has a distinct triangular dark brown to black mark extending medially from the dorsal part of this suture. Like E. helenae, E. irwini, and E. webbi, the anterior orbital seta is closer to the lunule edge than to the posterior seta. Like E. helenae, the anepisternum has a distinct brown pruinose spot at the base of the anepisternal seta. Like all species except $E$. frankadelia, the orbital setae are strong with the posterior seta slightly stronger than the anterior seta, and the anterior dorsocentral seta is closer to the transverse suture than to the middle seta. Like all species except $E$. albeto, the face lacks a median spot and the midtibia has 1 strong spur. In the male: the surstylus is thick basally then is abruptly thinned into a medially curved claw-like hook distally, is setose and pilose over the basal thicker part, is pilose over the base of the thinned hook, and the tip is sharp and bare; the aedeagus has its lateral edges evenly concave through its length, lacks a dorsal sharpened ridge, and the gonopore is broadly open; the hypandrium has paired posteriorly-directed lateral lobes extending into peg-like projections with 2 thickened setae at the tip; the paramere is absent.

Adults, ox, ㅇ. Body length 5.2-5.4 mm.

Head (Fig. 3E). 1.1-1.2 $\mathrm{X}$ higher than long, 1.4-1.5 $\mathrm{X}$ wider than high; eye as high as long. Vertex silvery grey pruinose; outer vertical seta as strong as anterior orbital seta, inner seta 1.4-1.5 X longer. Ocellar triangle covered with silvery grey pruinescence continuous with vertex. Ocellar setae strong, as long as anterior orbital seta but slightly thinner; proclinate, parallel-sided. Postocellar setae strong, subequal to ocellar setae. Occiput and median occipital sclerite silvery grey pruinose. Frons with anterolateral part with brown pruinescence visible in profile below fronto-orbital plate. Fronto-orbital plate densely covered with silvery grey pruinescence. Orbital setae strong; posterior seta 1.31.4 X longer than anterior; anterior seta arising slightly closer to edge of lunule than to posterior seta; anterior setae slightly closer together than posterior setae. Antennal scape, facial carina, and area lateral to antennal base pale yellow, with light dusting of silver pruinescence. Antennal pedicel and 1st flagellomere orange; 1st flagellomere 1.2-1.3 X longer than high; arista pubescent. Face yellow, with light dusting of silver pruinescence; antennal grooves with dark brown pruinose area below antenna and along dorsal part of ptilinial suture; ventral part of face with paired dark brown pruinose spots. Parafacial, gena, and postgena yellow with light covering of silvery white pruinescence; postgena with silvery grey pruinose stripe. Clypeus light brown. Maxillary palpus dark orange; subcylindrical; with black setulae.

Thorax. Scutum 1.2-1.3 X longer than wide; scutellum with width at base 1.3-1.4 X greater than length; scutum and scutellum mostly silvery grey pruinose, slightly darker silvery brown through median third of scutum and corresponding area at base of scutellum, 
orange spot posteromedially from postpronotal lobe, orange stripe through intra-alar area of mesonotum; postpronotal lobe through notopleuron to wing base silvery yellow. Pleural area pale silvery white pruinose; brown spot at base of anepisternal seta; dorsal part of anepisternum bronzy pruinose; brown pruinose stripe from anteroventral part of anepisternum through katepisternal setae. Distances between anterior and middle dorsocentral setae and between middle and posterior setae subequal, with anterior seta closer to transverse suture than to middle seta. Legs. Yellowish orange, except as noted. Coxae silvery grey pruinose. Forefemur silvery grey pruinose; ctenidium as evenly spaced (each $0.15-0.20$ $\mathrm{mm}$ apart) row of 8-11 setulae; posterior surface with 1-2 small setae. Foretibia with brown bands basally, sub-basally, and apically. Midfemur silvery grey pruinose on basal one-fifth, and with silvery grey pruinose band slightly beyond middle; brown band at midpoint, on ventral surface. Midtibia with brown bands basally, sub-basally (corresponding in position with band on femur), and apically; with 1 strong spur. Hindfemur silvery grey pruinose on basal quarter, with silvery brown pruinose band on anterior and anteroventral surfaces beyond middle and apically. Hindtibia with dark brown bands sub-basally (corresponding in position with band on femur) and apically. Wing. Length 4.5-4.6 mm; 2.3-2.6 $\mathrm{X}$ longer than high. Discal medial cell 3.8-4.0 X longer than crossvein dm-cu. Halter yellow.

Abdomen. Yellowish orange dorsally; length subequal to scutum. Lateral portion of tergite 1 (as part of syntergite $1+2$ ) dark silvery grey pruinose; lateral portions of tergites 2-5 silvery grey pruinose, with large brown spot visible from ventral view near tergal edge, and another large brown spot visible from dorsal view (both spots visible from lateral view). Sternites silvery grey pruinose; with sparse fine setulae; in female, sternites as wide as long, with slightly elongated setae along posterior edges.

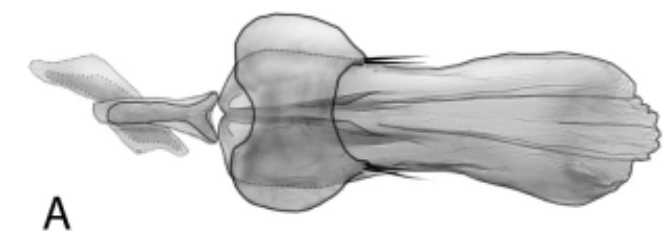

A

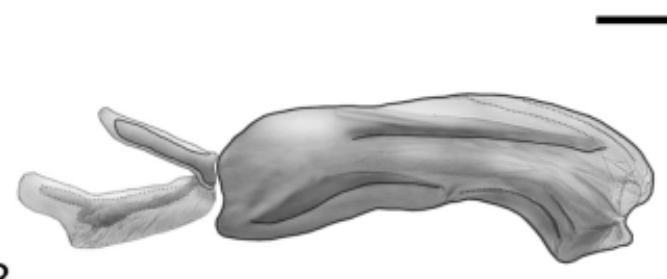

C

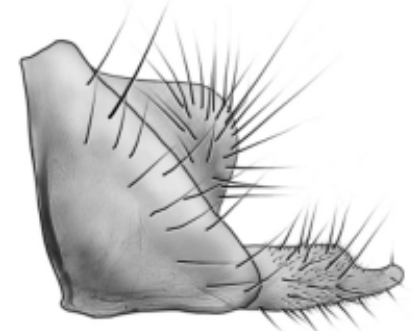

D

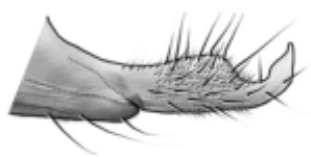

FIGURE 12. Evertomyia matilei, sp. nov. $\sigma^{x}$. Male genitalia. Scale bar $=0.2 \mathrm{~mm}$. A) Aedeagal complex, ventral view. B) Aedeagus, lateral view. C) Epandrial complex, lateral view. D) Surstylus, dorsal view. 
Male genitalia. Surstylus articulated with epandrium (Figs. 12C-D); parallel-sided through basal two-thirds until reaching abruptly thinned claw-like hook distally, which curves $90^{\circ}$ medially; setose and densely pilose over entire surface of basal two-thirds, thinned hook with small setulae and dense pile basally, distally sharpened tip bare. Aedeagus (Figs. 12A-B) with anterior and posterior ends subequal in width, but lateral edges evenly concave through length; lacking dorsal sharpened ridge, but bulging dorsally; lacking distinct ventral furrow; gonopore broadly open. Hypandrium (Fig. 12A) small, hourglass shaped, with paired posteriorly-directed lateral lobes extending into peg-like projection with 2 thickened setae at tip. Paramere absent. Aedeagal apodeme small, thin; branched posteriorly into 2 small arms; straight from lateral view. Ejaculatory apodeme slightly larger than aedeagal apodeme, but more lightly sclerotized.

Female terminalia. Sternite 8 (Figs. 13A-B) with length 1.2-1.3 X width; sides tapering anteriorly; heavily sclerotized only along anterior edge and lateral arms; paired central processes originating in anterior part, broadened and tapering only slightly distally, and extending slightly beyond posterior edge; lacking distal hooks; processes and medial portion setose. Tergite 8 lightly sclerotized. Spermathecae (Fig. 13C) small, with single spermatheca round and paired spermathecae elongated; single spermatheca $0.09 \mathrm{~mm}$ diameter, paired 0.06 X $0.11 \mathrm{~mm}$ each; paired spermathecae on short stalks after bifurcation.
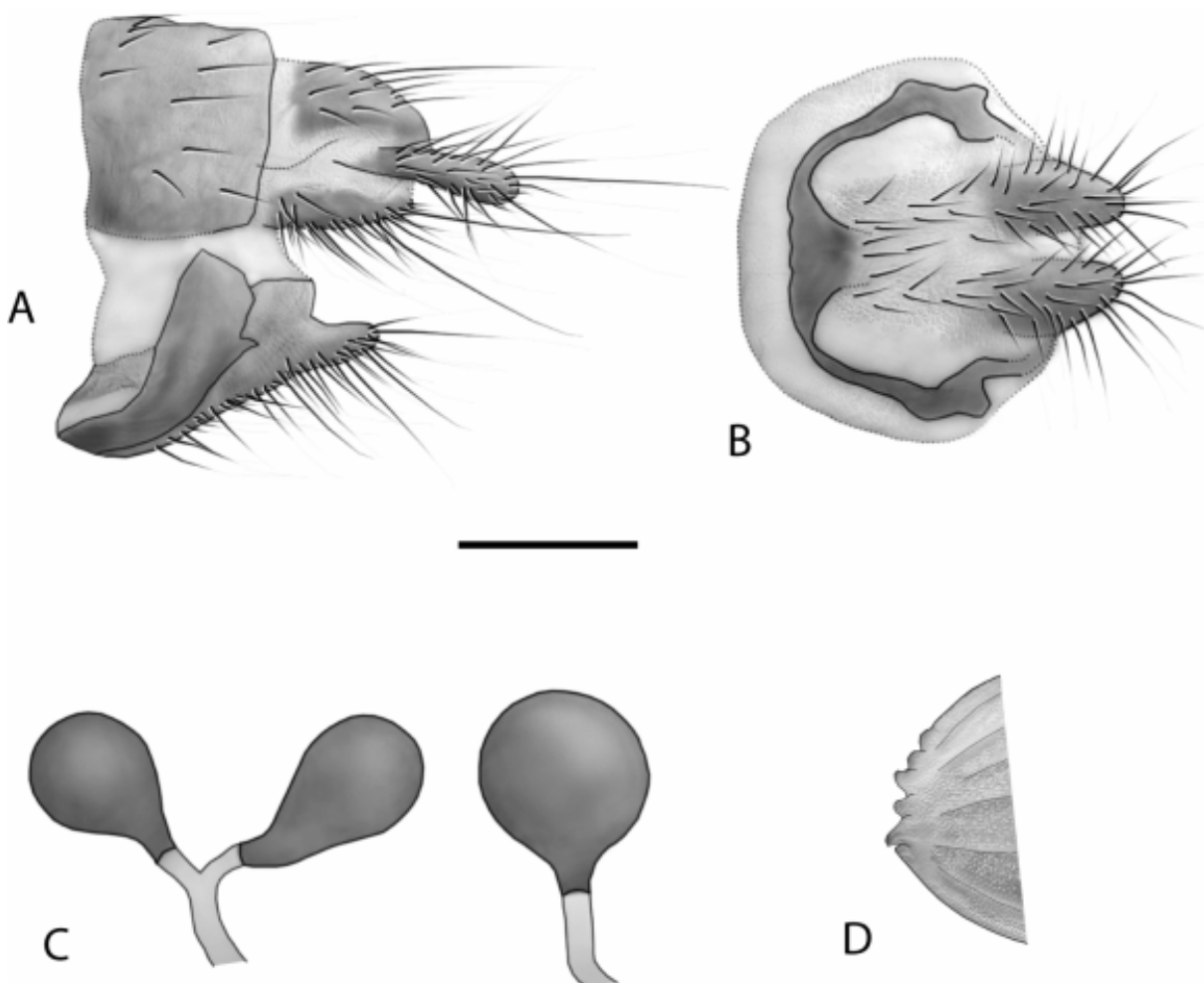

FIGURE 13. Evertomyia matilei, sp. nov. 우. Female genitalia and egg. Scale bar, A-B = $0.2 \mathrm{~mm}$; $\mathrm{C}-\mathrm{D}=0.1 \mathrm{~mm}$. A) Terminalia, lateral view. B) Terminalia, ventral view. C) Spermathecae. D) Egg, eclosion end, lateral view. 
Immatures. Egg. Micropylar end not protruding. Eclosion end with lobes reduced to pointed stubs (Fig. 13D).

Biology. Specimens of this species have been collected only in October and November. Two specimens were collected in Malaise traps.

Type material. Holotype $\sigma^{\star}$ (pinned, very good condition, dissected genitalia below in small glass tube of glycerin) deposited in MNHN with the following labels: "NEW CALDEDONIA / Rivière Bleue Prov. Pk. / km 21.9 Riv. Bleue road / 30 Oct-3 Nov 1992, 320 m / ME Irwin, DW Webb / E\&M Schlinger", "Malaise trap / in / Maquis de Crete", "LAUXANIIDAE / S.D. Gaimari specimen / 01000" (orange label), "SDG dissection / 904 o"”, "HOLOTYPUS / Evertomyia / matilei / Gaimari o"” (red label). Paratypes. Province Sud. Mont Koghi, 450-600 m (J. \& M. Sedlacek), 4-6.X.1967 [1 ơ]. (same collection data as holotype) Rivière Bleue Provincial Park, km 21.9 Riv. Bleue road, 320 m (M.E. Irwin, D.W. Webb, E. \& M. Schlinger), Malaise trap in Maquis de Crete, 30.X-3.XI.1992 [1우 (dissection 1205: SDG 001017)]. Upper La Ni Valley, 718 m (M. Schlinger), 2.XI.1992 [1 9]. Paratypes deposited in BPBM, INHS, and USNM.

Distribution. Known only from the southern part of the island, in the low to middle elevation rainforests of the Monts des Koghis and the Parc Provincial de la Rivière Bleue.

\section{Evertomyia webbi, sp. nov.}

(Figs. 3F, 14A-E, 15A-C)

Etymology. Named for the dipterist Dr. Donald W. Webb, my good friend and one of the collectors of this and several species of this genus.

Diagnosis. Like E. frankadelia, this species has weaker, divergent ocellar setae, the face lacks paired spots, the ptilinial suture and antennal groove are unmarked, the scutum and scutellum are brownish orange, lacking vittae or silvery grey pruinescence, and the anepisternum is pale without dark marks, although in this species is paler. Like E. helenae, $E$. irwini, and E. matilei, the anterior orbital seta is closer to the lunule edge than to the posterior seta. Like E. helenae and E. irwini, the antennal arista is short plumose. Like all species except $E$. frankadelia, the orbital setae are strong with the posterior seta slightly stronger than the anterior seta, and the anterior dorsocentral seta is closer to the transverse suture than to the middle seta. Like all species except $E$. albeto, the face lacks a median spot and the midtibia has 1 strong spur. Unlike all other species, the fronto-orbital plate lacks pruinescence and displays shiny ground color, and the face is silvery grey pruinose. In the male: the surstylus is subcircular in lateral view, is setose laterally, and is entirely pilose; the aedeagus only tapers distally, the ventral surface has a median longitudinal furrow; the hypandrium is a broad band with the anterior and posterior edges parallel; the paramere is present, tusk-like, curved outwards, and has several small setulae at the base. In the female: sternites 2-5 are less than $2 \mathrm{X}$ broader than long; sternite 8 is elongated but tapering anteriorly, with anteriorly-directed lateral arms, and the paired central processes are slightly elongated, each with a distal hook. 
Adults, ox, ㅇ. . Body length 5.7-7.1 mm.

Head (Fig. 3F). 1.3-1.4 X higher than long, 1.6-1.8 X wider than high; eye slightly higher than long. Vertex orange, but darker brown behind ocellar triangle to postocellar setae; outer vertical seta as strong as anterior orbital seta, inner seta 1.4-1.6 X longer. Ocellar triangle covered with brown pruinescence continuous with vertex. Ocellar setae weak, half length of anterior orbital seta and much thinner; divergent. Postocellar setae strong, nearly as strong as anterior orbital seta. Occiput and median occipital sclerite orange. Frons with anterolateral part with light dusting of silvery white pruinescence visible in profile below fronto-orbital plate. Fronto-orbital plate shiny brownish-orange, lacking pruinescence. Orbital setae strong; posterior seta 1.2-1.5 X longer than anterior; anterior seta arising slightly closer to edge of lunule than to posterior seta; anterior setae slightly closer together than posterior setae. Antennal scape, facial carina, and area lateral to antennal base pale yellow, with light dusting of silvery white pruinescence. Antennal pedicel brown; 1st flagellomere brown with orange basally, 1.5-1.7 X longer than high; arista short plumose, with longest rays $1.2-1.5 \mathrm{~mm}$ and $0.6-0.8 \mathrm{X}$ height of $1 \mathrm{st}$ flagellomere. Face dark, covered with pale silvery grey pruinescence; antennal grooves unmarked. Parafacial and gena dark, covered with pale silvery grey pruinescence; postgena orange, covered with silvery grey pruinescence. Clypeus dark brown. Maxillary palpus brownish; subcylindrical, nearly spatulate; with black setulae.

Thorax. Scutum 1.1-1.3 X longer than wide; scutellum with width at base 1.5-1.8 X greater than length; scutum and scutellum brownish orange dorsally, fading abruptly to nearly yellow at lateral edges. Pleural area entirely pale yellowish orange, as on lateral edge of scutum. Distances between anterior and middle dorsocentral setae and between middle and posterior setae subequal, with anterior seta closer to transverse suture than to middle seta. Legs. Yellowish orange, except as noted. Forefemur darker orange to brown on distal third, with patch of greyish brown pruinescence on anterodorsal surface; ctenidium as evenly spaced (each $0.19-0.23 \mathrm{~mm}$ apart) row of 13-16 setulae; posterior surface with short row of smaller setae. Foretibia with brown bands basally, sub-basally, and apically. Midtibia with 1 strong spur. Wing. Length 5.3-6.3 mm; 2.4-2.7 X longer than high. Discal medial cell 3.9-4.2 X longer than crossvein dm-cu. Halter yellow with darkened knob.

Abdomen. Dark greyish brown pruinose (some specimens vary in having certain areas, especially along midline and on distal segments, with reduced or no pruinescence, showing orange ground color; in most extreme case, dark pruinescence only present laterally and along posterior portion of each tergite); slightly shorter than scutum. Sternites yellowish orange; with sparse fine setulae; in female, sternites 2-5 1.7-1.8 X broader than long, with slightly elongated setae along posterior edges.

Male genitalia. Surstylus articulated with epandrium (Figs. 14D-E); subcircular from lateral view; posterior edge slightly sharpened; entirely pilose; setose laterally and on both sides of posterior edge. Aedeagus (Figs. 14A-B) evenly thick through basal half, then 
tapering distally; ventral surface with median longitudinal furrow to broadly open gonopore; dorsally with median longitudinal ridge. Hypandrium (Fig. 14A) a broad band with anterior and posterior edges parallel, with posterior edge slightly concave. Paramere (Figs. 14A, C) present, tusk-like, curved outwards; with several small setulae at base. Aedeagal apodeme normal, thick; branched posteriorly into 2 arms, appearing as "Y"; curvature such that ventral surface concave from lateral view. Ejaculatory apodeme subequal to aedeagal apodeme.
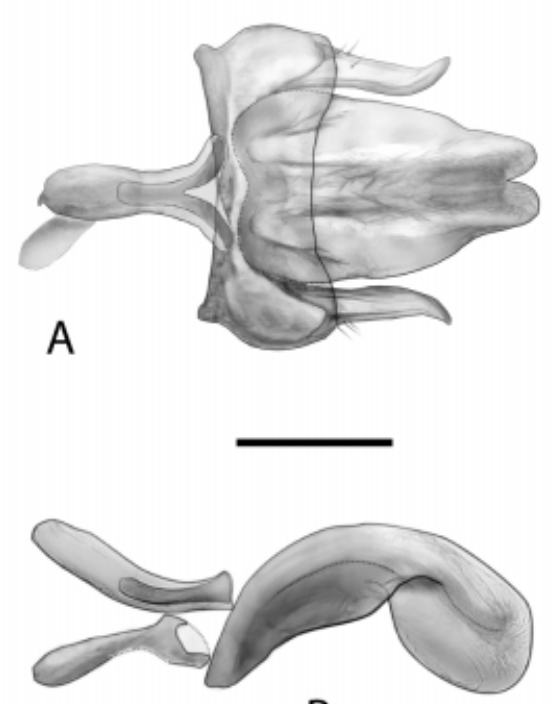

B
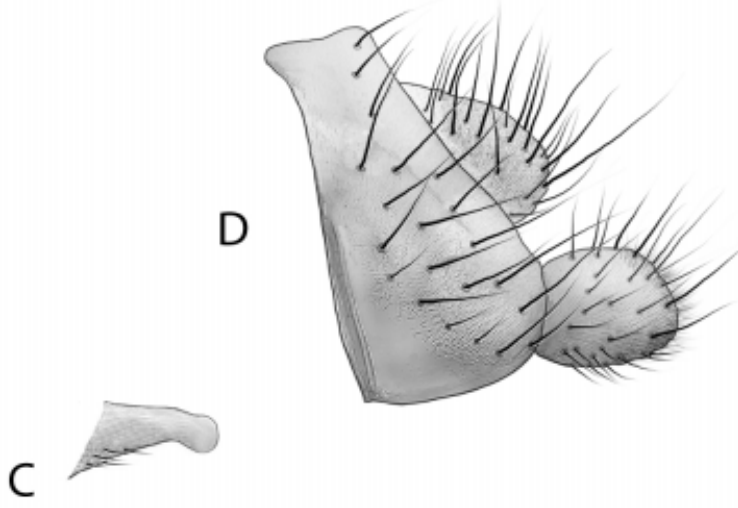

$\mathrm{E}$

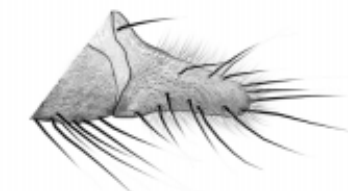

FIGURE 14. Evertomyia webbi, sp. nov. ${ }^{\star}$. Male genitalia. Scale bar $=0.2 \mathrm{~mm}$. A) Aedeagal complex, ventral view. B) Aedeagus, lateral view. C) Paramere, lateral view. D) Epandrial complex, lateral view. E) Surstylus, dorsal view.

Female terminalia. Sternite 8 (Figs. 15A-B) elongate but tapering anteriorly, width $0.6 \mathrm{X}$ length at posterior end to $0.25 \mathrm{X}$ length anteriorly; with only anteriorly-directed lateral arms sclerotized, with posterior part densely covered with small bumps; paired central processes originating on posterior third of sternite 8 , short (but longer than wide) and extending slightly beyond posterior edge of sternite, with medially-oriented distal hooks; process setose. Spermathecae round; single spermatheca $0.13 \mathrm{~mm}$ diameter, paired 0.10 mm each; paired spermathecae on short stalks after bifurcation (as in Fig. 13D).

Immatures. Egg. Micropylar end slightly enlarged, globose (Fig. 15C). Eclosion end with distinct lobes, 3 on each side.

Biology. Specimens of this species have been collected in all months from July through April, except September. One specimen was collected in association with a spe- 
cies of Psychotria L. (Rubiaceae), but specimens are most commonly collected using Malaise traps, often placed across forest paths and along streams.
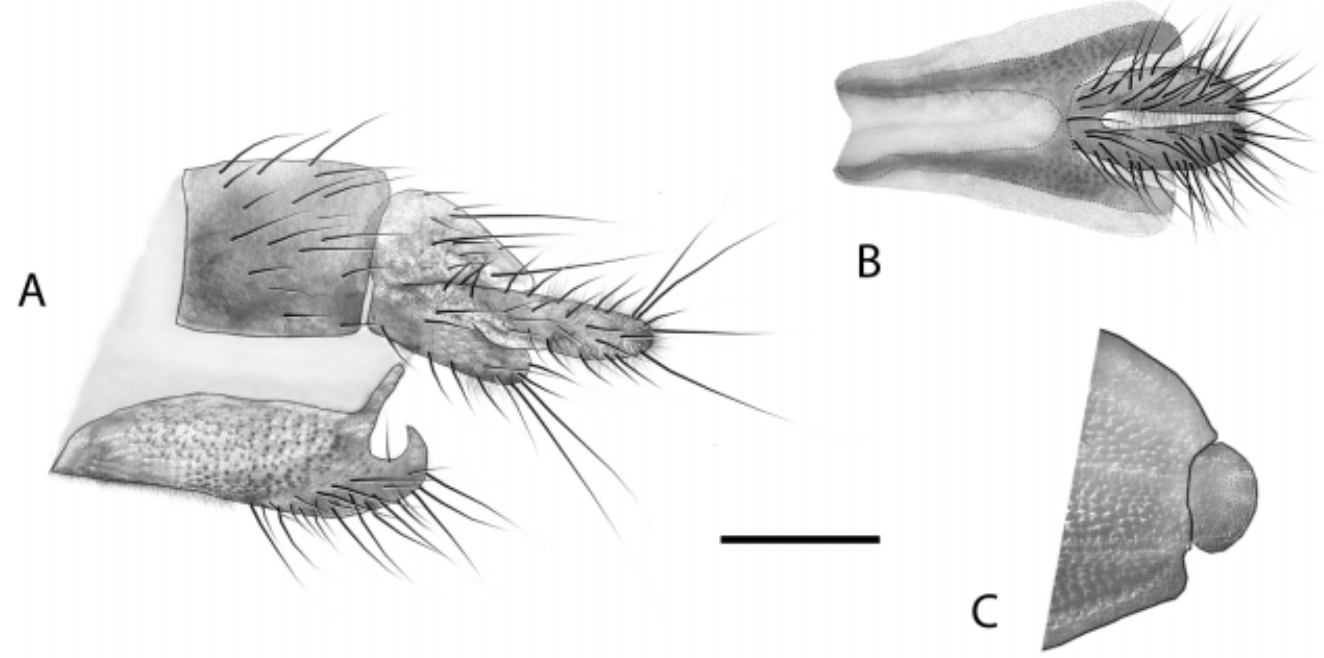

FIGURE 15. Evertomyia webbi, sp. nov. 우. Female genitalia and egg. Scale bar, A-B = $0.2 \mathrm{~mm}$; C $=0.1 \mathrm{~mm}$. A) Terminalia, lateral view. B) Terminalia, ventral view. C) Egg, micropylar end, lateral view.

Type material. Holotype ${ }^{x}$ (pinned, very good condition) deposited in BPBM (BPBM 16,530) with the following labels: "Noumea, New Caled. / Nov. 1940", "HOLOTYPUS / Evertomyia / webbi / Gaimari o" (red label). Paratypes. Province Nord. 13 km SE KaalaGomén, 2046'07"S, 164²7'26"E, 100 m (M. E. Irwin, D. W. Webb), small Malaise trap across road in dry shrub, 20.I.1996 [1 $\left.\mathrm{o}^{\top}\right] .22 \mathrm{~km}$ NW Hienghène, trail to Mont Panié, 600 m (D.W. Webb, E. \& M. Schlinger), Malaise trap in tropical forest, 11-25.XI.1992 [10]. Col des Roussettes, 300-400 m (N.L.H. Krauss), 29.I.1969 [1 ㅇ‥ Headwaters of Houailou

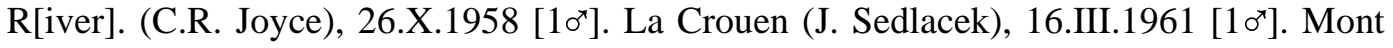
Mandjanié, 5.3 km WSW Puébo, $550 \mathrm{~m}$ (D. W. Webb), Malaise trap in tropical forest, 9-

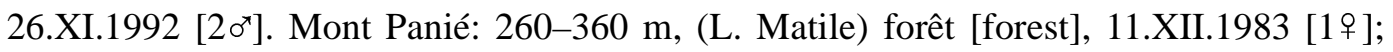
360 m (L. Matile), 11-16.XII.1983 [1 ㅇ]. Mont Panié trail (N.L.H. Krauss), 8-9.II.1963 [19]. On heights between Thio [Prov. Sud] \& Nakety [Prov. Nord] (C. R. Joyce), 12.XI.1958 [20x 3 ㅇ]. Tiwaka, Poindimié, $20 \mathrm{~m}$ (L. Matile), forêt galerie [forest gallery], 23.XI.1983 [1우. Yiambi [Yambé], NE, 1-50 m (J. \& M. Sedlacek), 15.X.1967 [1 $10^{\rtimes}$ ]. Province Sud. 10 km NW Sarraméa, 21³4'55"S, 16547'50"E, 485 m (M. E. Irwin, D. W. Webb), Malaise trap across forest road, 21.I.1996 [1우 (dissection 907: SDG 01006)].

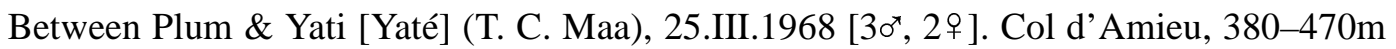

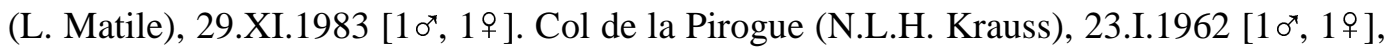



[1우, 11.II.1976 [1 ox, 1ㅇ]; 400-600 m (N.L.H. Krauss), II.1973 [1ㅇ]; 500 m (C. Yoshimoto), 26-30.I.1963 [1 o $\left.^{\star}\right]$, (M. Sedlacek), 23-27.VIII.1967 [1 $\left.10^{x}\right]$, (C. Yoshimoto \& N.L.H. Krauss), Malaise trap, 26-30.I.1963 [1 ㅇ], (R. Straatman), Malaise trap, 4.XII.1963 [1 ㅇ]; 500-700 m (R. Straatman), 1.XII.1963 [1 ㅇ]; \pm 600 m (R. Straatman), 30.XI.1963 [1 $\circ^{x}$;

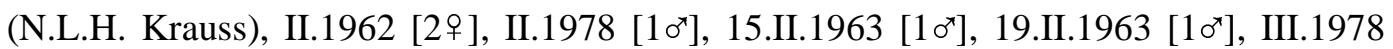

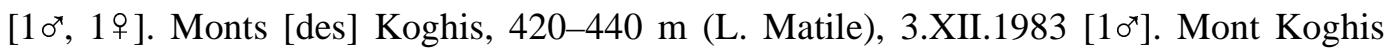
[Koghi], 17 km NNE Nouméa: 22¹0'34"S, 166³0'17"E, 425 m (M.E. Irwin, D.W. Webb, E.I. Schlinger), Malaise trap across path in rainforest, 8-10.I.1996 [1 o $\left.^{\top}\right], 10-11 . I .1996$

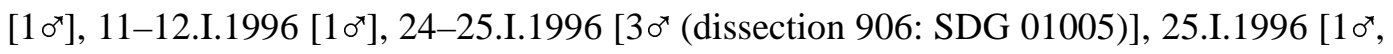

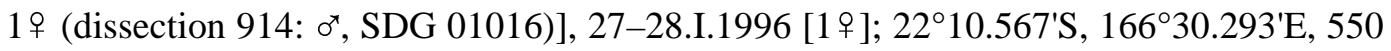
m (M.E. Irwin, D.W. Webb), Malaise trap, 17.XI.1998 [1 ơ] $^{x} 500$ m (D. W. Webb), Malaise trap in tropical forest, 5-15.XI.1992 [6 $\left.0^{x}\right], 15-20 . X I .1992$ [1 o $^{x}$; 500 m (M.E. Irwin, D.W.

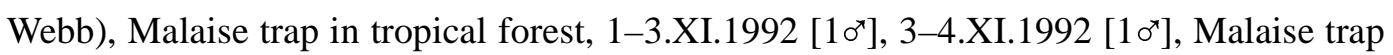

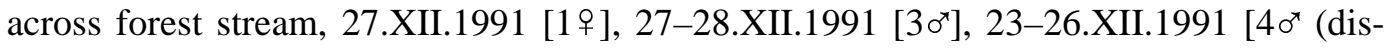
section 905: SDG 01004)]. Monts des Koghis, 300-600 m (J.L. Gressitt \& T.C. Maa),

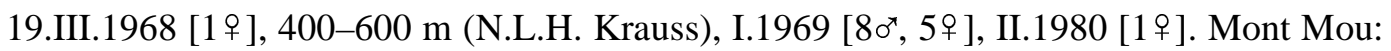
(N.L.H. Krauss), 11.II.1962 [1 9]; Foret Inf. [= inférieur] [lower elevation forest], 160250m (L. Matile), bord ruiss. [= ruisseau] [stream edge], 6.XII.1983 [30 (dissection 913: SDG 01015)]. Nouméa (R. Straatman), 22-23.XI.1963 [10]. Plaine des Lacs area (C.R.

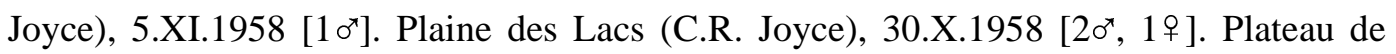
Dogny: 150-900 m (N.L.H. Krauss), 4.II.1971 [10, 1 ] ] 400 m (J.L. Gressitt), Psychotria [plant association], 10.IV.1973 [1 9]; (J.L. Gressitt \& T.C. Maa), 29.III.1968 [20']; (N.L.H. Krauss), 31.I.1969 [1 o $^{\star}$. Rivière Bleue Provincial Park: 28 km NW Yaté (M.E. Irwin, D.W. Webb), Malaise trap across running stream, 23-27.XII.1991 [1 ㅇ]; Env. [= environs de] [near] Yaté (L. Matile), ft. [= forêt] cotière [sloping forest], bord ruiss. [= ruisseau] [stream edge], 8.XII.1983 [1 $10^{\star}, 1$ ㅇ]; Forêt de la Thy, 150-250 m (L. Matile), 28.XI.1983 [1 $0^{x}, 1$ \% ], Forêt de la Thy (J. Chazeau), piège de Malaise [Malaise trap], 21.IV.1981 [1 $\circ^{x}$; Parc 5, $150 \mathrm{~m}$ (L.B. de Larbogne, J. Chazeau), piège de Malaise [Malaise trap], forêt humide sur alluvions [humid forest on river bank], 13-28.I.1986 [1 o $^{\star}, 4$ 우]; Parc 6, $150 \mathrm{~m}$ (L.B. de Larbogne, J. Chazeau, A. et S. Tillier), piège de Malaise [Malaise trap], forêt humide sur alluvions [humid forest on river bank], 5-20.I.1987 [6 $60^{\star}$ (dissection 912: SDG 01014)], 160 m, (L. B. de Larbogne, J. Chazeau), piège de Malaise [Malaise trap], forêt

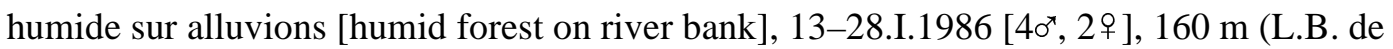
Larbogne, J. Chazeau, R. et S. Tillier), piège de Malaise [Malaise trap], forêt humide sur alluvions [humid forest on river bank], 18.VII-1.VIII.1986 [1우; Parc 7, 170 m (L.B de Larbogne, J. Chazeau), fôret humide sur pente [humid forest on slope], 19.XI-4.XII.1985

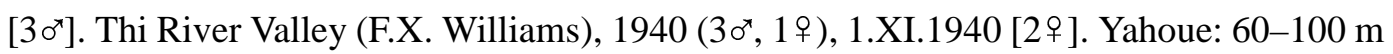

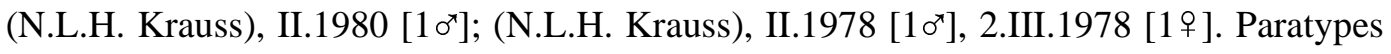
deposited in AMNH, AMSA, ANIC, BMNH, BPBM, CASC, CAUC, CNCI, CSCA, 
DEBU, EMEC, HNHM, INHS, KUEC, MCZC, MHNG, MNHN, MZSP, NHMW, NMSA, QMBA, UCDC, USNM, ZISP, ZMHB, and ZMUC.

Distribution. Found in both the Province Nord and Province Sud, only at lower elevations (below $700 \mathrm{~m}$ ). In the north, found in the rainforest areas near Kaala-Gomén, on Mont Panié, on Mont Madjanié, in Col des Roussettes, in La Crouen, in the Thio-Nakety vicinity, in the Yambé vicinity, near the headwaters of the Houailou River, and in Tiwaka near Poindimié. In the south, found in the rainforest areas of Col d'Amieu, Col de la Pirogue, the Yaté vicinity, the Yahoue vicinity, the Monts des Koghis, Mont Mou, Nouméa, the Plaine des Lacs vicinity, the Plateau de Dogny, the Thi River valley, and the Parc Provincial de la Rivière Bleue.

\section{Phylogenetics}

Cladistic analysis of the data matrix in Table 1 resulted in one most parsimonious cladogram (Fig. 16) of length 53, CI of 0.79 (0.73, excluding autapomorphies), RI of 0.72, and $\mathrm{RC}$ of 0.57 . The topology remained stable through successive approximations character weighting, stabilizing after one iteration. Because homoplasy increases with number of taxa in a parsimony analysis, the regression equation of Sanderson \& Donoghue (1989) was used for comparison of the consistency index. The calculated value of 0.76 for seven taxa is slightly higher than the value indicated in the current analysis, excluding autapomorphies, so the amount of homoplasy is slightly more than predicted for an analysis with this number of taxa. The high retention index indicates that a high proportion of the potential synapomorphies in the data matrix are present as homologies on the cladogram. The resulting Bremer support indices for each node are displayed on the cladogram in Fig. 16.

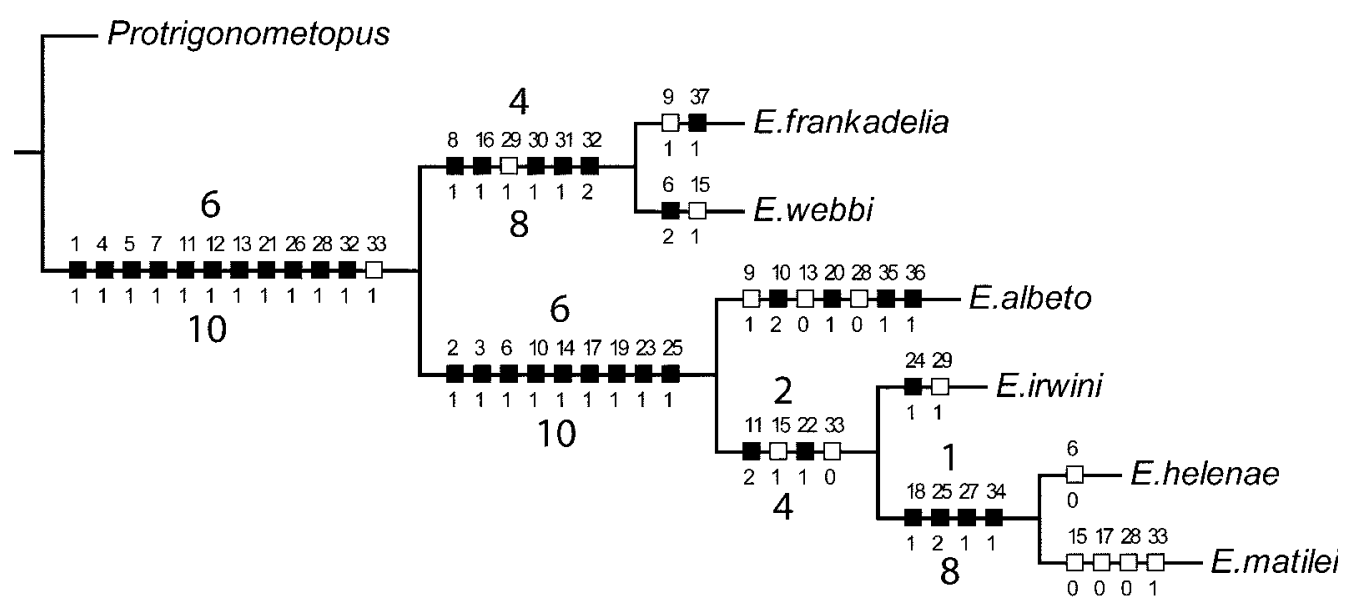

FIGURE 16. Single most parsimonious cladogram for Evertomyia, showing character state changes under ACCTRAN character optimization. Characters are numbered as in the text; hash marks are as follows: black = forward change with no homoplasy; white $=$ change with homoplasy. Unweighted Bremer support indices are indicated above each branch, and rescaled Bremer support indices are indicated below each branch. 
The monophyly of Evertomyia is supported by nine synapomorphies (and several additional that undergo reversals within the tree) relative to the outgroup, a Bremer support index of 6 for the genus node, and a rescaled Bremer support index of 10. Note though, that some characteristics are also present in other unrelated lauxaniid taxa, as homoplasy is commonplace throughout this family. The unreversed synapomorphies include: the placement of the ocellar triangle anterior to the vertex (ch. 1), the bare frontal vitta (ch. 4), the raised fronto-orbital plate (ch. 5), the presence of inclinate, reclinate, and reclino-inclinate setulae on the anterior part of the fronto-orbital plate (ch. 7), the presence of an antennal groove (although the coloration is represented by two states) (ch. 11), the dorsal part of the face is pinched inwards into a facial carina (ch. 12), wing vein $\mathrm{A}_{1}+\mathrm{CuA}_{2}$ is long, visible nearly to the wing margin (ch. 21), the surstylus of the male is articulated with the epandrium (ch. 26), and the presence of lobes on sternite 8 of the female (although the state of the lobe is represented by two states) (ch. 32).

Within the topology of Evertomyia species (Fig. 16), two distinct clades are supported by synapomorphies, including some genitalic characters. For example, the clade of frankadelia $+w e b b i$ is supported by the absence of the pruinose spot below the frontoorbital plate (ch. 8), the lack of silvery grey pruinescence on the scutum (ch. 16), the elongated condition of sternite 8 in the female (ch. 30), the presence of medially oriented pointed tips on sternal lobes in the female (ch. 31), and the presence of long thin lobes on sternite 8 of the female (ch. 32, state 2). The clade of albeto + irwini + helenae + matilei is supported by the strong (ch. 2), proclinate and parallel-sided (ch. 3) ocellar setae, the darkened edge of the ptilinial suture (ch. 10), the presence of paired spots on the ventral part of face (ch. 14), the presence of dorsocentral vittae (with an apparent reversal in $E$. matilei, although instead of pruinose vittae the entire area is pruinose) (ch. 17), the basal, sub-basal, and apical brown bands on the tibiae (ch. 19), and the presence of lateral spots on the abdominal tergites (ch. 23). The clade of irwini + helenae + matilei is supported by the distinctly darkened antennal groove (ch. 11, state 2), the entirely yellow halter (ch. 22), and the lobes of sternite 8 in the females do not extend beyond the posterior edge of the sternite (ch. 33, reversal to state 0 ). The sister-group relationship between helenae + mat$i l e i$ is supported by the presence of a distinct spot at the base of the anepisternal seta (ch. 18), the basally thick, then abruptly tapering surstylus in the male (ch. 25), the concave anterior edge of the hypandrium (ch. 27), and the distinctly reduced spermatheca (the single, unpaired one) to less than $0.09 \mathrm{~mm}$ in diameter (ch. 34).

\section{Acknowledgments}

I heartily thank Michael Irwin (University of Illinois) for spearheading collecting efforts in New Caledonia that resulted in much of this material. Very special thanks are also extended to his fellow collectors in these efforts, especially Donald Webb (INHS) and Evert Schlinger (Emeritus, University of California, Berkeley). Special thanks are also 
extended to Michel Baylac and Jeanne Charbonnel (MNHN), Neil Evenhuis and Keith Arakaki (BPBM), Dan Bickel and David McAlpine (AMSA), and Chris Burwell (QMBA) for their hospitality and assistance during my recent visits to study this and other material and for the necessary loans, and to Bernhard Merz (MHNG), Wayne Mathis (USNM), and one or more anonymous reviewers of the manuscript. This paper is based upon work supported by the National Science Foundation under DEB Award No. 0075206. Any opinions, findings, and conclusions or recommendations expressed in this publication are those of the author and do not necessarily reflect the views of NSF.

\section{References}

Bremer, K. (1994) Branch support and tree stability. Cladistics, 10, 295-304.

Carpenter, J.M. (1988) Choosing among equally parsimonious cladograms. Cladistics, 4, 291-296.

Curran, C.H. (1929) Diptera collected by Prof. and Mrs. Cockerell in New Caledonia and Fiji Islands. American Museum Novitates, 375, 1-15.

Frey, R. (1927) Philippinische Dipteren. IV. Fam. Lauxaniidae. Acta Societatis pro Fauna et Flora Fennica, 56, 44 pp.

Gaimari, S.D. \& M.E. Irwin. (2000) Phylogeny, classification, and biogeography of the cycloteline Therevinae (Diptera: Therevidae). Zoological Journal of the Linnean Society (London), 129, 129-240.

Hendel, F. (1938) Muscaria Holometopa (Dipt.) aus China im Naturhistorischen Reichsmuseum zu Stockholm. Arkiv för Zoologi, 30A (3), 13 pp.

Kertész, K. (1900) Beiträge zur Kenntnis der Indo-Australischen Sapromyza-Arten. Természetrajzi Füzetek, 23, 254-276.

Malloch, J.R. (1940) Some Sapromyzidae (Diptera) from the Solomon Islands and New Caledonia. Novitates Zoologicae, 42, 131-146.

McAlpine, J.F. (1981) Morphology and Terminology - Adults, pp 9-63. In: McAlpine, J.F., Peterson, B.V., Shewell, G.E., Teskey, H.J., Vockeroth, J.R., \& Wood, D.M. (coords.), Manual of Nearctic Diptera, Volume 1. Research Branch, Agriculture Canada, Ottawa, Monograph 27, $674 \mathrm{pp}$.

Nixon, K.C. (2002) WINCLADA version 1.00.08. Published by the author. Ithaca, NY. Available from www.cladistics.com (April 2002).

Sanderson, M.J. \& M.J. Donoghue. (1989) Patterns of variation in levels of homoplasy. Evolution, 43, 1781-1795.

Shewell, G.C. (1987) Lauxaniidae, pp 951-964. In: McAlpine, J.F. (ed.), Manual of Nearctic Diptera, Volume 2. Research Branch, Agriculture Canada, Ottawa, Monograph 28, 675-1332.

Stuckenberg, B.R. (1971) A review of the Old World genera of Lauxaniidae (Diptera). Annals of the Natal Museum, 20, 499-610.

Swofford, D.L. (1999) PAUP*: Phylogenetic Analysis Using Parsimony (*and Other Methods), Beta Version 4.0b2. Sinauer Associates, Sunderland, Massachusetts.

Swofford, D.L. \& W.P. Maddison. (1987) Reconstructing ancestral states under Wagner parsimony. Mathematics and Bioscience, 87, 199-299.

Thompson, C.G. (1869) Diptera. Species nova descripsit, pp 443-614. In: Kongliga svenska fregatten Eugenies resa omkring jorden under befäl af C.A. Virgin, åren 1851-1853, Vol. 2 (Zoologi), Section 1 (Insecta). “1858.” P.A. Norstedt \& Söner, Stockholm, 617 pp. 